\title{
$\beta$-Peptide foldamer helices with tailored diameters
}

\author{
Ph.D. Thesis
}

\section{Éva Szolnoki}

Supervisor

Prof. Dr. Tamás Martinek

Institute of Pharmaceutical Chemistry

Institute of Pharmaceutical Analysis

University of Szeged 
"School is for learning to learn, so the thrist for knowledge can rouse, to get to know the delight of the well done work, to feel the taste of tension of creation and to find the work that will be relished."

Albert Szent-Györgyi 


\section{Table of contents}

Table of contents.................................................................3

Scientific publications and lectures...............................................3

Full papers related to the thesis............................................................... 4

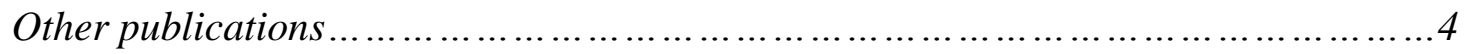

Scientific lectures related to the thesis............................................... 5

Abbreviations and symbols...................................................6

1. Introduction and aims.....................................................

2. Literature background......................................................9

$2.1 \quad$ Peptidic foldamers..................................................... 9

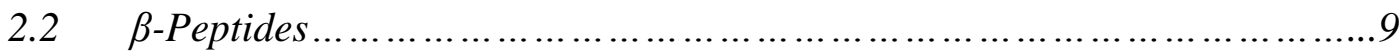

2.2.1 Helical secondary structures...................................11

2.2.2 Higher-ordered helical motifs.................................16

2.2.3 Pharmaceutically active $\beta$-peptides.........................17

2.2.4 Bioactive $\beta$-peptide helices..................................18

$2.3 \quad$ Solid-phase synthesis of $\beta$-peptides .....................................20

3. Methods.......................................................................21

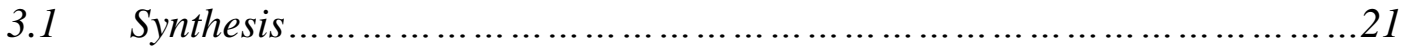

3.2 Structure investigations ...............................................22

3.3 Aggregation-related measurements......................................23

4. Results and discussion....................................................24

4.1 Sculpting the $\beta$-peptide H12 helix via bicyclic side-chains..................24

4.2 Self-association-driven large-diameter helix formation ........................31

4.3 Foldameric $\beta$-H18/20p mixed helix stabilized by head-to-tail contacts: a way to higher-order structures..........................................38

4.4 Intermolecular helix-helix association .....................................45

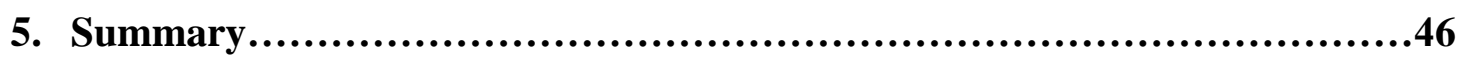

Acknowledgements............................................................48

References........................................................................49

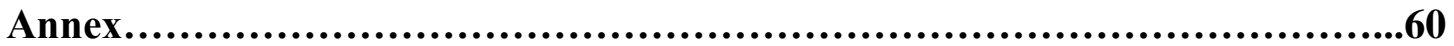




\section{Scientific publications and lectures}

\section{Full papers related to the thesis}

1. Hetényi, Z. Szakonyi, I. M. Mándity, É. Szolnoki, G. K. Tóth, T. A. Martinek and F. Fülöp:

Sculpting the $\beta$-peptide foldamer H12 helix via a designed side-chain shape Chem. Commun. 2009, 177-179.

IF.: 5.504*

2. É. Szolnoki, A. Hetényi, T. A. Martinek, Z. Szakonyi and F. Fülöp:

Self-association-driven transition of the $\beta$-peptidic H12 helix to the H18 helix

Org. Biomol. Chem. 2012, 10, 255-259. IF.: 3.568

3. É. Szolnoki, A. Hetényi, I. M. Mándity, F. Fülöp and T. A. Martinek:

Foldameric $\beta$-H18/20P mixed helix stabilized by head-to-tail contacts: a way to higher-order structures

Eur. J. Org. Chem. 2013, 17, 3555-3559.

IF.: 3.065

\section{Other publications}

4. T. A. Martinek, É. Szolnoki, Z. Zalán and F. Fülöp:

Synthesis and steric structure of pyrrolidine- and piperidine-fused 1,3,4,2-

oxadiazaphosphinanes

Arkivoc 2007, (v), 202-209.

IF.: 1.253

5. E. Wéber, A. Hetényi, B. Váczi, É. Szolnoki, R. Fajka-Boja, V. Tubak, É. Monostori and T. A. Martinek:

Galectin-1-Asialofetuin interaction is inhibited by peptides containing the Tyr-XxxTyr motif acting on the glycoprotein

ChemBioChem 2010, 11, 228-234. IF.: 3.945

*The impact factors for the year of publication are given. 


\section{Scientific lectures related to the thesis}

1. Szolnoki Éva

$\beta$-peptid H12 hélix stabilizálása tervezett oldallánc kölcsönhatásokkal

MTA Peptidkémiai Munkabizottság Ülése

Balatonszemes, 2008. május 14-16.

2. Szolnoki Éva

$\beta$-peptid H12 hélix stabilizálása tervezett oldallánc kölcsönhatásokkal

XXXI. Kémiai Előadói Napok

Szeged, 2008. október 27-29.

3. Szolnoki Éva

Biciklusos oldalláncok hatása $\alpha$-hélix mimetikumok stabilizálására és önrendeződésére

MTA Peptidkémiai Munkabizottság Ülése

Balatonszemes, 2009. május 26-28.

4. Éva Szolnoki, Zsófia Hegedüs, Zsolt Szakonyi, Tamás A. Martinek, Ferenc Fülöp:

Effects of bicyclic residues on $\beta$-peptide secondary structures

COST, Foldamers: Building blocks, structure and function

Szeged, Hungary, September 24-26, 2009, Abstr.: P02

5. Szolnoki Éva, Hegedüs Zsófia, Martinek Tamás, Szakonyi Zsolt, Fülöp Ferenc

Biciklusos oldalláncok hatása $\beta$-peptidek helikális másodlagos szerkezeteire

Congressus Pharmaceuticus Hungaricus XIV.

Budapest, 2009. november 13-15. Abstr.: P-10

6. Éva Szolnoki, Zsófia Hegedüs, Tamás A. Martinek, Zsolt Szakonyi, Ferenc Fülöp

$\beta$-Peptide helical structures induced by bicyclic amino acid residues

COST, Foldamers: From design to protein recognition

Bordeaux-Pessac, France, January 25-28, 2010, Abstr.: p. 16.

7. Éva Szolnoki, A. Hetényi, Tamás A. Martinek, Zsolt Szakonyi, Ferenc Fülöp

$\beta$-Peptidic H18 helices

COST, Foldamers: Synthesis and structure of functional materials

Bellaterra (Barcelona), Spain, April 7-9, 2011, Abstr.: OC18 


\section{Abbreviations and symbols}

2D

3D

ACPC

$\mathrm{ACHC}$

$\mathrm{ABHC}$

$\mathrm{ACBC}$

ACHEC

AIDS

APC

APiC

AU

B3LYP

Boc

Bzl

COSY

DBU

DCM

DIPEA

DLS

DMF

DMSO

DNA

DOSY

ECD

Fmoc

FT-IR

HATU

HIV

MC

MD

MOE

MS

NMR

NOESY

PPI

RNA

ROESY

RP-HPLC

SPPS

TAR

${ }^{t} \mathrm{Bu}$

TEM

TFA

TNF

TOCSY two-dimensional

three-dimensional

2-aminocyclohexanecarboxylic acid

2-aminocyclopentanecarboxylic acid

2-amino-6,6-dimethyl bicyclo[3.1.1]heptane-3-carboxylic acid

2-aminocyclobutanecarboxylic acid

cis-2-aminocyclohex-3-enecarboxylic acid

acquired immune deficiency syndrome

4-aminopyrrolidine-3-carboxylic acid

4-aminopiperidine-3-carboxylic acid

analytical ultracentrifugation

Becke, three-parameter, Lee-Yang-Parr exchange-correlation functional tert-butoxycarbonyl

benzyl

correlation spectroscopy

1,8-diazabicyclo[5.4.0] undec-7-ene

dichloromethane

N,N-diisopropylethylamine

dynamic light scattering

N,N-dimethylformamide

dimethylsulfoxide

deoxyribonucleic acid

diffusion-ordered spectroscopy

electronic circular dichroism

9-fluorenylmethoxycarbonyl

Fourier transform infrared spectroscopy

O-(7-azabenzotriazol-1-yl)-N,N,N,N'-tetramethyluronium

hexafluorophosphate

human immunodeficiency virus

Monte Carlo

molecular dynamics

molecular operating environment

mass spectrometry

nuclear magnetic resonance

nuclear Overhauser effect spectroscopy

protein-protein interaction

ribonucleic acid

rotating frame Overhauser effect spectroscopy

reversed-phased high-performance liquid chromatography

solid-phase peptide synthesis

transcriptional activator-responsive element

tert-butyl

transmission electron microscopy

trifluoroacetic acid

tumour necrosis factor

total correlation spectroscopy 


\section{Introduction and aims}

Biopolymers (peptides, proteins, nucleic acids or carbohydrates) are able to form distinct conformations in order to exert different biological functions. ${ }^{1-7,13}$ In the absence of structural motifs, many recognition, transport and signal transduction or receptor-binding processes can not be implemented, and an understanding of the control over their specific well-organized 3D structure is therefore indispensable..$^{3,4,7}$

Foldamers are regarded as synthetic polymer architectures that have the feature of adopting well-defined periodic compact structures, and could therefore be rivals of the natural polymer systems both in their functions and applications. ${ }^{3,7}$ The most significant representatives of these non-natural self-organized biomimicking systems are the $\beta$-peptides, which are built up from $\beta$-amino acid units. ${ }^{8-10}$ The different types and derivatives of $\beta$-amino acids occupy a specific field in synthetic chemistry. The $\beta$-peptides are the closest relatives of the natural $\alpha$ peptides, but the insertion of a methylene group between the peptide bonds enhances the conformational freedom of these systems and allows the existence of numerous programmable secondary structures ( a wide range of helices, strands and turn motifs). ${ }^{12-20}$ Since helices represent the central structural form in the biological macromolecules such as DNA and proteins, the most thoroughly studied secondary structure motif of the $\beta$-peptides is also the helix. ${ }^{11}$ Various promising examples for biological or pharmaceutical application have already been found in the literature among helically folded $\beta$-peptides, ${ }^{13}$ such as selective antibacterial amphiphiles, RNA-binding foldamers and inhibitors of protein-protein interactions. However, the search for novel possible applications continues to show a growing tendency. ${ }^{21}$

Basically three helical structures, the $\mathrm{H} 14, \mathrm{H} 12$ and $\mathrm{H} 10 / 12$ play crucial roles regarding biological activity as displaying a close resemblance to the $\alpha$-helix ${ }^{12,13,18,19,29}$. They can be induced by a special backbone substitution and a specific backbone stereochemical pattern. ${ }^{20,68}$ The H14 helix is the most throughly studied helical structure and there are many ways to stabilize it. In contrast with the H14 helix, the H12 helix can be obtained only through the incorporation of a sufficient number of the five-membered ring-containing cyclic $\beta$-amino acid residues (ACPC) with trans relative backbone configuration. This helix type is the best mimic of the $\alpha$-helix, and one of our major aims was therefore to find another method to stabilize the H12 helix. For this purpose, we used $\beta$-amino acid derivatives with special side-chain shapes. ${ }^{65}$

In many cases, secondary structure transitions can be obtained among biopolymers. This conformational polymorphism, such as the random coil $\rightarrow$ helix $^{22,23}$ or the helix $\rightarrow$ helix $^{24,25}$ 
transition, is a very important feature in the natural protein systems, which is mostly connected to a certain biological function. An excellent example of this is the voltage-gated ion channels, whose function correlates unequivocally with a 310 -helix $\rightarrow \alpha$-helix transition. ${ }^{26}$ In this case, the helix geometry is affected by the external stimulus. In the artificial $\alpha$-peptidic chains, the control over the 310 -helix $\rightarrow \alpha$-helix equilibria takes place in a concentration-dependent way $^{27}$ and with the change of the solvent polarity ${ }^{28}$, but an example of a chain-length-dependent transition of the 310 -helix $\rightarrow \alpha$-helix is also known. Conformational transitions have also been described for peptidic foldamers. ${ }^{29,57}$ The transition from the $\mathrm{H} 10$ helix to the H14 helix occurs with the increase of the peptidic chain length for oligomers having trans-ACHC in the sequence. ${ }^{30}$ Our aim was to prove the existence of the helix transition and its influencing factors for foldameric oligomers containing the ACHC analogue trans-ABHC and $\beta^{3}$-hSer residues in various patterns.

The $\beta$-peptide foldamers have the propensity to adopt higher-ordered structure motifs, like helical bundles of $\alpha$-peptides. ${ }^{18,31}$ It has been shown that $\beta$ and $\alpha \beta$-peptidic sequences are able to form quaternary structures with self-assembling helical building blocks. ${ }^{32-35}$ These processes are very similar to the solvophobic interaction-driven tertiary/quaternary-structure formation observed for natural proteins. We planned to investigate the folding and the possibility of higher-ordered structure formation in alternating heterochiral transACPC-containing $\beta$-peptide foldamer systems.

\section{Literature background}

\subsection{Peptidic foldamers}


The process of folding occurring in the natural polymer systems (peptides, proteins or nucleic acids) results in well-defined 3D conformations. ${ }^{1,3,7,9}$ Foldamers are non-natural oligomeric molecules that have a strong tendency to adopt specific compact structures, ${ }^{12,13}$ similarly to the biopolymers. The conformationally ordered states of foldamers are stabilized by non-covalent forces (hydrogen-bonds, hydrophobic, electrostatic and van der Waals interactions) between non-adjacent monomer units. ${ }^{17,20}$ Foldamers can be divided into two major categories: (i) bioinspired and (ii) abiotic foldamers. ${ }^{14}$ The most prominent representatives of the bioinspired ones are the aliphatic peptidic foldamers, whose structures show a close resemblance to natural peptides. Within this class, the following scaffolds can be distinguished: peptoids, ${ }^{7,14,17} \beta^{-10,13,36-39}$ and $\gamma$-peptides, ${ }^{7,40-43}$ azapeptides, ${ }^{44-47}$ oligoureas ${ }^{48-50}$ and aminoxy peptides. ${ }^{51,52}$ Conformationally constrained monomers have been used in bioinspired foldamers, such as polyprolines ${ }^{53-54}$ and hybrid oligomer sequences with $\alpha \beta,{ }^{55-59}$ $\alpha \gamma^{60-62}$ or $\beta \gamma^{63-65}$ repeating units can also be found in this family (Figure 1).
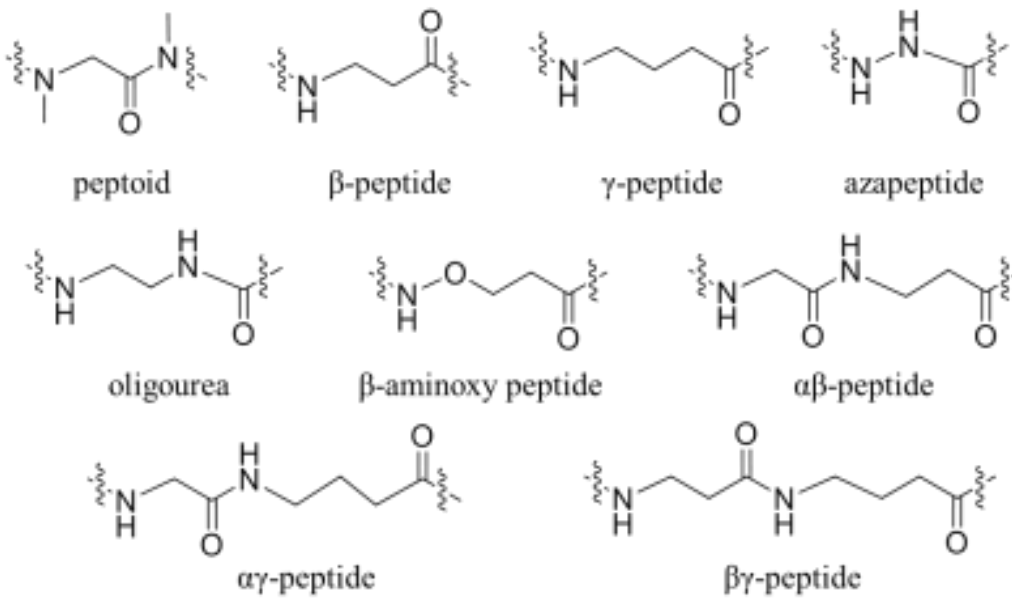

Figure 1. Peptidic foldamer backbones

\section{$2.2 \quad \beta$-Peptides}

The $\beta$-peptides present a particular appeal among foldameric structures. They are the closest relatives of the $\alpha$-peptides with an additional insertion of a methylene group between the peptide bonds capable of forming stabilizing, intramolecular hydrogen-bonds. ${ }^{9}$ The $\quad \beta$ peptides are built from $\beta$-amino acid units, which can be conveniently achieved via synthetic routes. ${ }^{18,66,67}$ The backbone substitution pattern of $\beta$-peptides is more diverse than that of their $\alpha$-analogues; it can be mono- or disubstituted or part of a cyclic ring system. ${ }^{19,69,70}$ The chirality offers a further tool to enhance the structural diversity (Figure 2). 


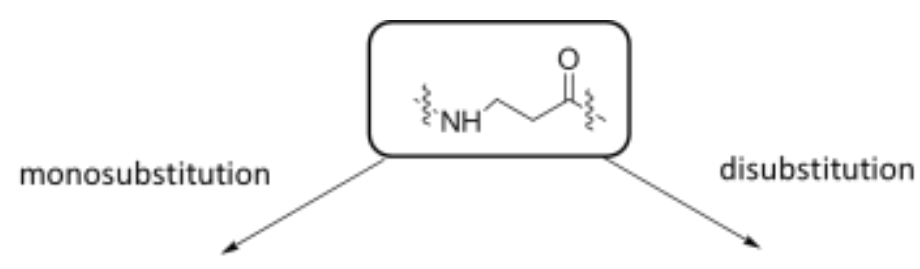<smiles>[Y4]NC([R])CC(=O)CC([R])N[Z19]</smiles>

(S)- $\beta_{3}$-peptide<smiles>[R2]C(CNC)C(=O)O</smiles>

(S)- $\beta_{2}$-peptide
(R)- $\beta_{3}$-peptide<smiles>[R]C(CN[14CH3])C(=O)O</smiles>

(S)- $\beta_{2}$-peptide

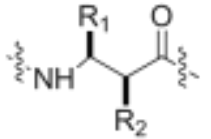

$(S, S)-\beta_{2,3}$-peptide<smiles>[R]C(NC)C([R])C(=O)CC</smiles>

$(R, R)-\beta_{2,3}$-peptide

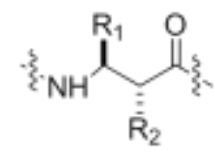

$(S, R)-\beta_{2,3}$-peptide<smiles>[R]C(NC)C([R])C(=O)O</smiles>

(R,S)- $\beta_{2,3}$-peptide

Figure 2. Possible backbone substitutions of $\beta$-peptides

$\beta$-Peptides can therefore adopt various secondary structures at even shorter chain lengths ${ }^{13,71}$ relative to the natural $\alpha$-peptides, including helices, sheets and turn-like conformations (Figure 3). The side-chain substitution pattern, ${ }^{20}$ the stereochemistry of the backbone, ${ }^{68}$ and various non-covalent forces (steric repulsions, hydrogen-bonds, electrostatic, aromatic-aromatic interactions and solvophobic effects) offer a powerful means of controlling the secondary structure, thereby allowing the rational design of foldamers.

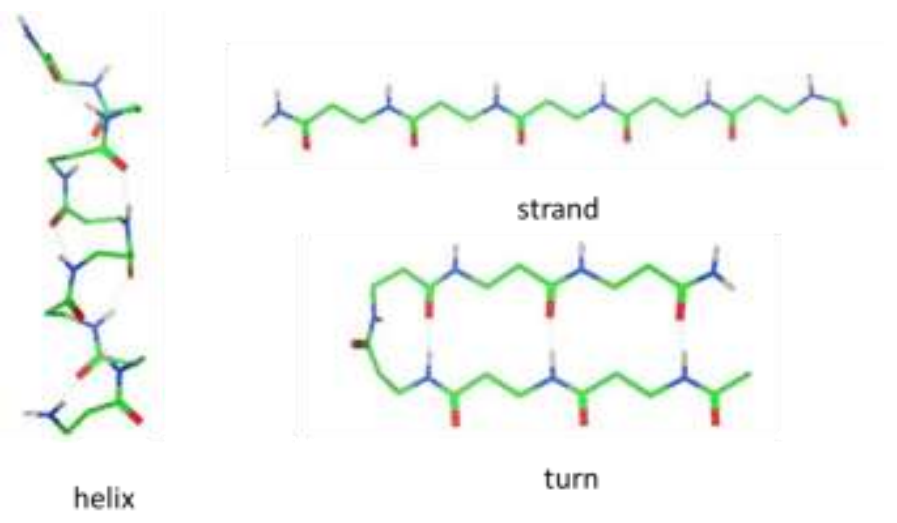

Figure 3. Selected secondary structure motifs

\subsubsection{Helical secondary structures}

The conformational properties of the $\beta$-peptides can be defined by the backbone torsion angles $(\varphi, \theta$ and $\psi)$ in Balaram's convention. ${ }^{72}$ Helical conformations of $\beta$-peptides adopt a 
gauche conformation of the torsion angle $\theta$, which can be obtained with $\beta^{3}, \beta^{2}$ and $\beta^{2,3}$ or cyclic residues with syn relative backbone configuration (Figure 4).

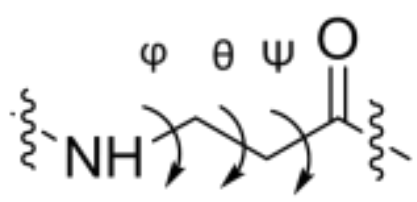

Figure 4. Effects of substituents on the torsional angle $\theta$

Several periodic structures can be distinguished, whose nomenclature is based on the numbers of atoms in the hydrogen-bonded pseudorings. ${ }^{73-74}$ The experimentally observed helix types of $\beta$-peptides ${ }^{18,68}$ are shown in Figure 5.

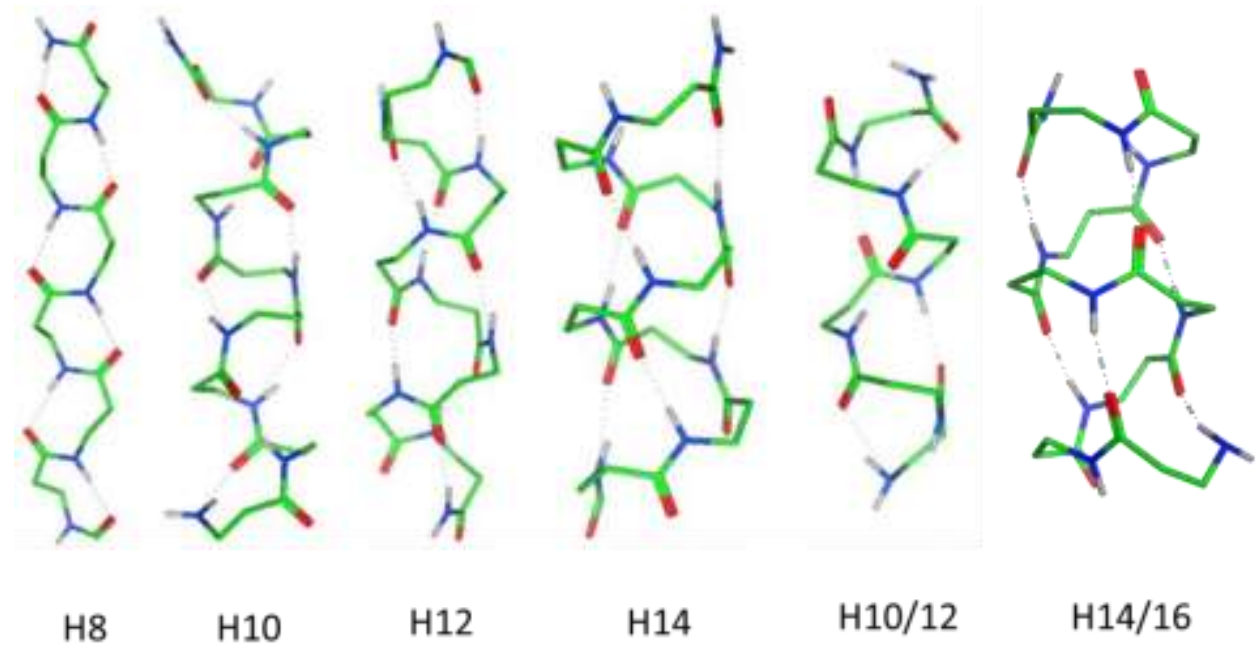

Figure 5. The described helical secondary structures of $\beta$-peptides

The Gellman group reported the first helical conformation, which was the H14 helix ${ }^{9}$ (Figure 6). Short $\beta$-peptides containing the conformationally constrained alicyclic trans2-aminocyclohexanecarboxylic acid (trans-ACHC) adopted stable H14 helices in organic solvents and in the solid state. ${ }^{30,75-77}$ Trans-4-aminopiperidine-3-carboxylic (trans-APiC) acid residues can also be incorporated into the sequence to form an H14 helix in aqueous solution. ${ }^{78}$ Interestingly, Ortuno and co-workers revealed the ability of cis-2aminocyclobutanecarboxylic acid (cis-ACBC) monomers to promote H14 helical folding when incorporated into $\beta$-peptides. ${ }^{79}$ Seebach and co-workers proved that acyclic $\beta^{3}$-amino acids 
derived from the natural L- $\alpha$-amino acids can also stabilize left-handed $(M)$ H14 helices in organic solvents. ${ }^{80-83}$ This helix type is stabilized by hydrogen-bonds between amides at positions $(i)$ and $(i+2)$ in the sequence. The incorporation of conformationally constrained cyclohexane-containing amino acids ${ }^{84}$ into the peptide chain or the presence of disulfide bridges $^{85}$ and salt bridges ${ }^{86-89}$ between the side-chains or other alternative methods ${ }^{90}$ can strongly improve the helix stability in the aqueous medium.

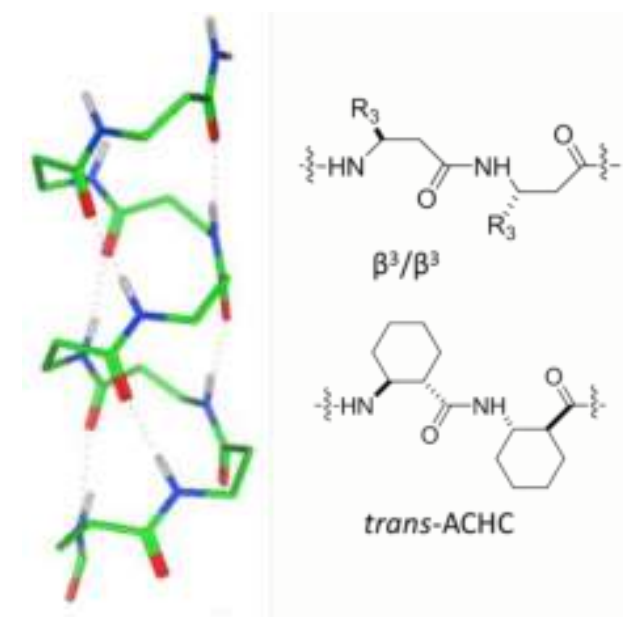

Figure 6. The H14 helix and its possible building blocks

After the discovery of the H14 helix, systematic conformational searches and molecular dinamics calculations of the cyclopentane-containing trans-2-aminocyclopentanecarboxylic acid (trans-ACPC) revealed a new helical structure, the H12 helix ${ }^{91-98}$ (Figure 7). This helix type is stabilized by hydrogen-bonds between the residues at positions $(i)$ and $(i+3)$ in the sequence. As few as six ACPC residues are able to form a reasonably stable H12 helix. Unfortunately, $\beta$-peptide helices consisting of this amino acid are not stable in water. To solve this problem, trans-4-aminopyrrolidine-3-carboxylic acid (trans-APC) was prepared and incorporated into the $\beta$-peptides along with the ACPC residues. ${ }^{99-101}$ Application of azaACPC residues provides a further way to increase the water solubility and stability. ${ }^{102}$ The Aitken group found that the cyclobutane side-chain topology plays an important role in the H12 helix-forming propensity of $\beta$-peptides. Hexameric and octameric structures of trans-ACBC residues displayed a tendency to form a well-defined $\mathrm{H} 12$ helical conformation. ${ }^{103}$ Winkler et al. have also reported the formation of the H12 helix type for ethanoanthracene-based peptides due to steric repulsion interactions of the side-chains in organic solvents. ${ }^{104}$ 

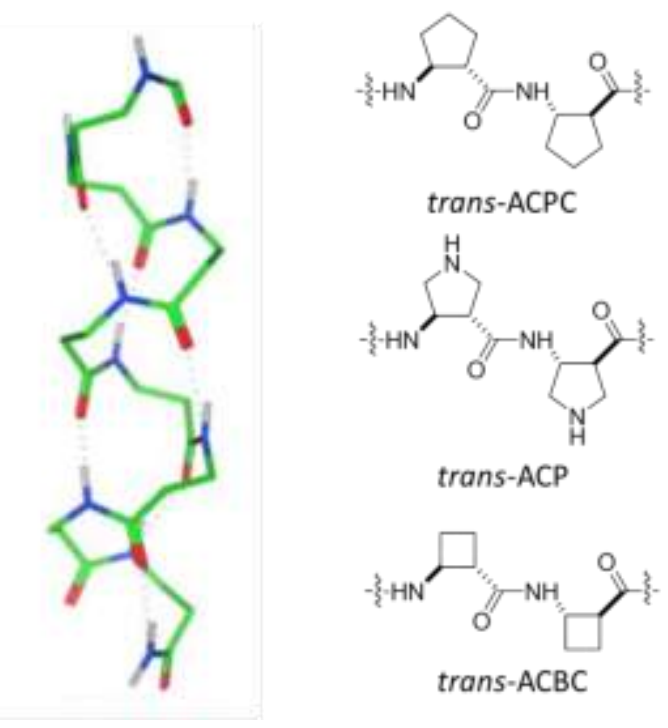

trans-ACP

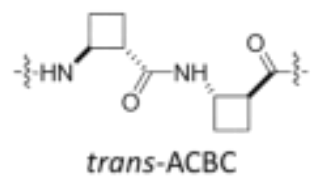

Figure 7. The $\mathrm{H} 12$ helix and the utilized $\beta$-amino acid units

The $\beta$-amino acid monomers with the four-membered ring constraint are also able to stabilize the H10 helix (Figure 8). The Fleet group reported the formation of this helix type for $\beta$-peptides containing $\beta$-amino acids with the oxetane ring in non-polar solvents. ${ }^{105}$ In contrast with the former helices, the amino and the carbonyl substituents are cis on the four-membered ring. The six-membered ring-containing trans-ACHC oligomers also adopt the $\mathrm{H} 10$ helix in the tetrameric range, while the H14 helix appears only at longer chain-lengths. ${ }^{30}$

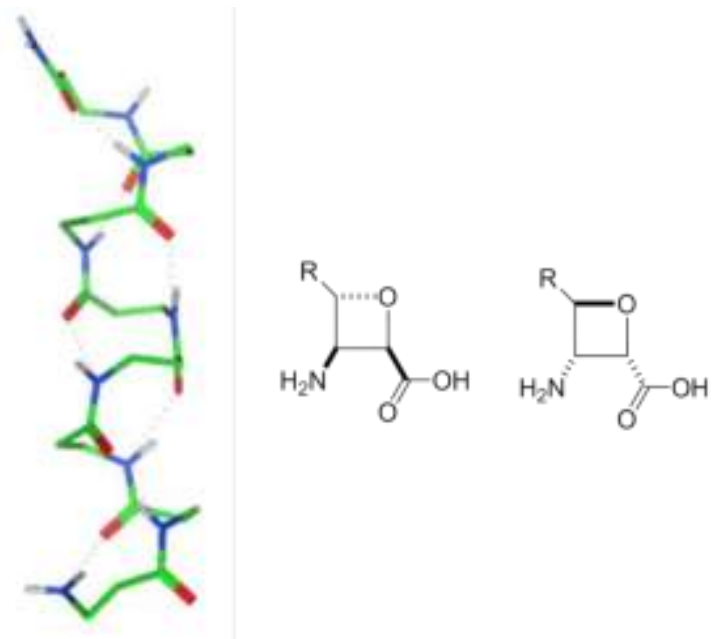

Figure 8. The H10 helix and its oxetane ring-containing monomer

The trans-ACBC units show a clear tendency to form 8-membered hydrogenbonded-rings in dipeptides such as the short oligomers of the achiral monomer $1-$ (aminomethyl)cyclopropanecarboxylic acid. ${ }^{106,107}$ Longer oligomers are able to adopt a regular 
H8 helix. Peptides derived from nucleoside $\beta$-amino acids ${ }^{108}$ can also form this structure (Figure 9).
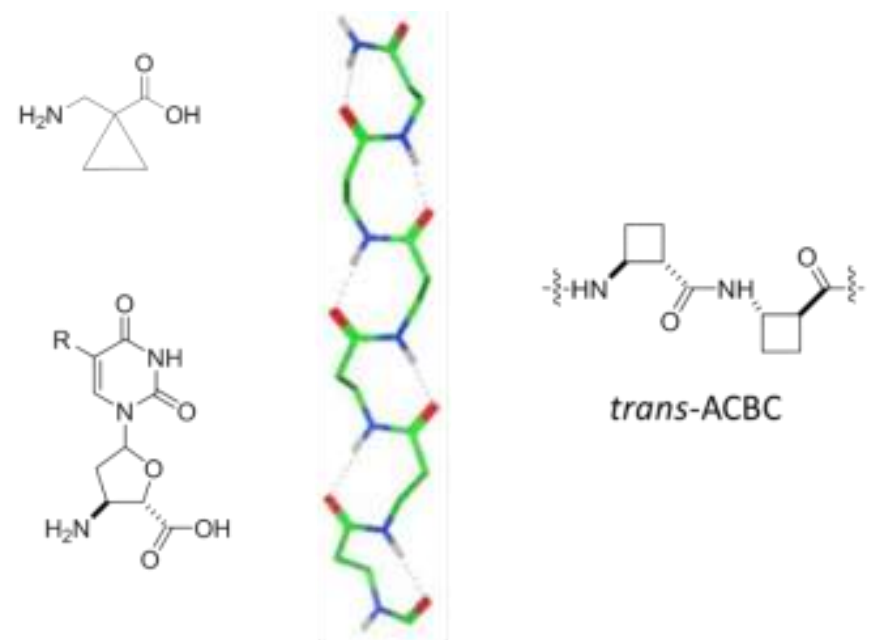

Figure 9. The H8 helical conformation and its building units

Two major mixed helix types have been described so far among the $\beta$-peptides. Coupling of the $\beta^{2}$ - and $\beta^{3}$-monosubstituted amino acids in an alternating way resulted in the formation of a unique mixed helical structure, the H10/12 helix. The characteristic feature of this helix is an intertwined network of 10- and 12-membered hydrogen-bonded rings (Figure 10). The H10/12 helix ${ }^{109-113}$ is more stable than the H14 helix. The same helix geometry was found in $\beta$-peptides constructed from alternating heterochiral cis-ACPC residues.

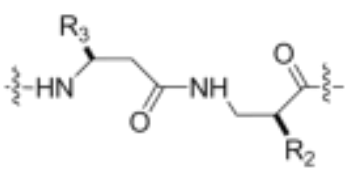

$\beta^{3} / \beta^{2}$

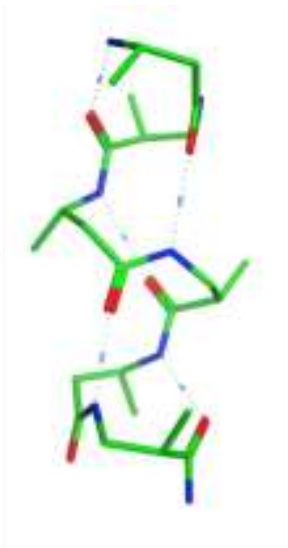

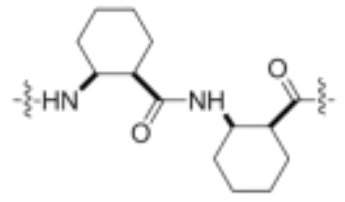

cis-ACHC

Figure 10. The H10/12 helix forming building blocks

The helix can tolerate the 6-membered cyclic residues as well. The

cis2-aminocyclohex-3-enecarboxylic acid monomers (cis-ACHEC) are able to promote the formation of the H10/12 helix ${ }^{114}$ with an alternating backbone configuration (Figure 11), but the cis-ACHC residues were observed to decrease the stability of the H10/12 helix. 

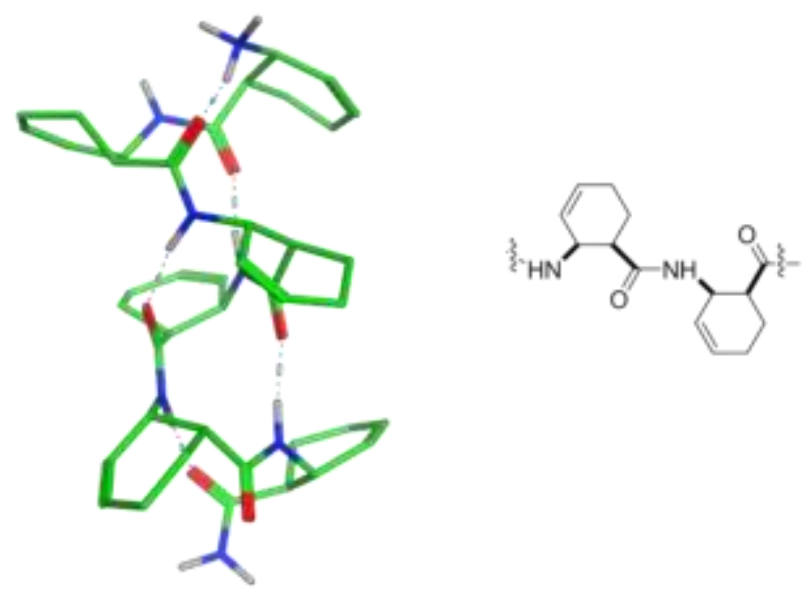

Figure 11. Tolerance of the cis-ACHEC residues in the mixed H10/12 helix

According to de novo helix design, the application of stereochemical patterning rules led to newer periodic secondary structure among $\beta$-peptides. The large-diameter H14/16 helix ${ }^{68}$ can be achieved by linking of the cis- and trans-ACPC residues or cis-ACPC and open-chain $\beta^{3}$-amino acid residues (Figure 12).
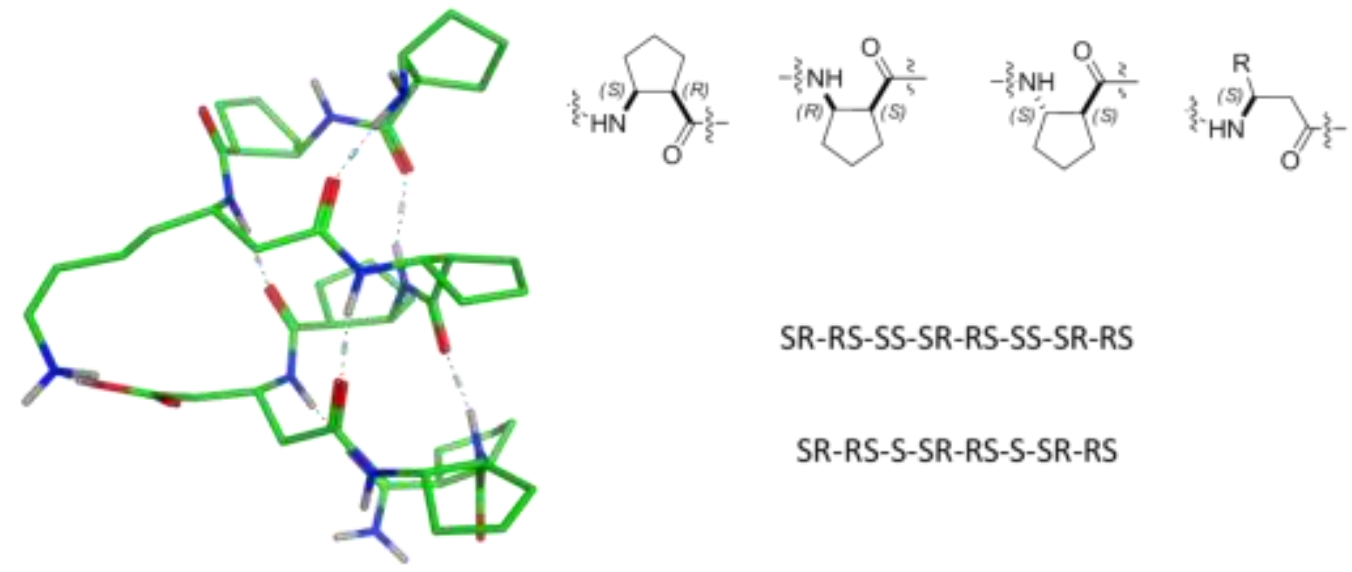

SR-RS-SS-SR-RS-SS-SR-RS

SR-RS-S-SR-RS-S-SR-RS

Figure 12. De novo designed H14/16 helix and its sequences

\subsubsection{Higher-ordered helical motifs}

The structural features and biological functions of the biopolymers are closely related to their highly ordered conformation, which enables the formation of tertiary and quaternary structures. The tertiary structure motifs potentially available for $\beta$-peptide foldamers are closely 
analogous with those well known for the natural protein systems: helical bundles and pleated sheet sandwiches. ${ }^{3,18}$

The formation of helical bundles was observed for the first time in the solid state, which afforded the first direct observation of a peptidic foldamer quaternary structure. AU and X-ray

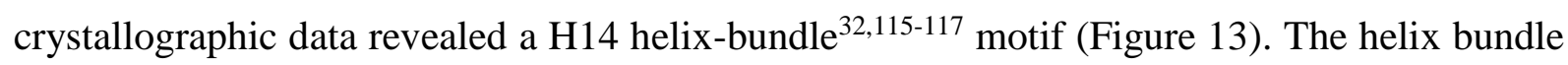
structure formation was also found for an amphiphilic H14 decamer sequence, stabilized by cyclic side-chains in aqueous solution, and for hydrophobic H14 helix oligomers of tetramerhexamer size, where hydrophobic attractive forces drove the self-assembly in $\mathrm{MeOH} .{ }^{118}$

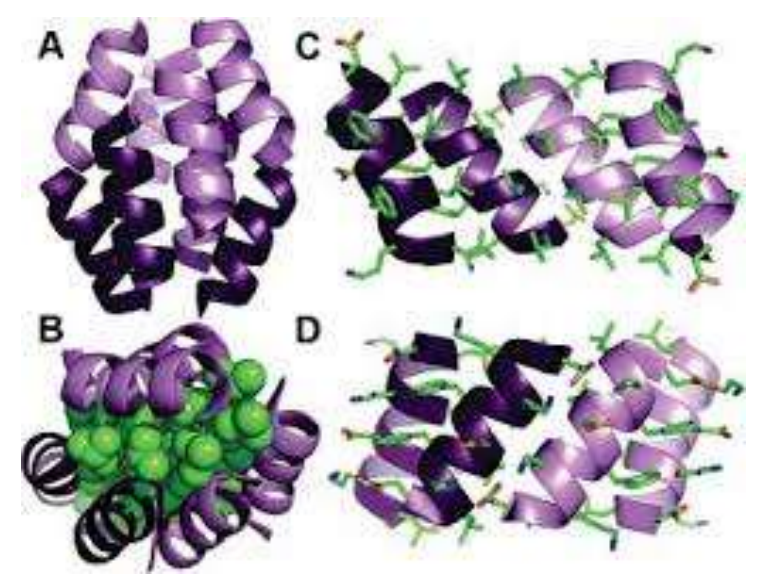

Figure 13. Different views of the $\beta$-H14 helical bundle

Besides the solvent-dependent self-association of amphiphilic helices, other approaches are also available for the stabilization of helix bundles. ${ }^{119-122}$ In covalently functionalized H14 helices, a reversible self-association is driven by the hydrogen-bonding between the nucleobase pairs. ${ }^{123}$ A helix dimer formation through complexation of the zinc ion was carried out by the incorporation of zinc-binding motifs in the $\beta$-peptide sequence. ${ }^{124}$ Crystal engineering has been elegantly applied for the molecular architecture of helices. ${ }^{125}$

Trimeric or tetrameric helix-bundle structures have been reported for $\alpha \beta$-chimera sequences. ${ }^{126-128}$ Interestingly, vertically amphiphilic H14-helices constructed from transACHC residues were shown to form helical bundles in the solution phase, as proved by NMR and dynamic light scattering (DLS) measurements. ${ }^{129}$ Transmission electron microscopy (TEM) images revealed the formation of multilamellar vesicles as further evidence of selfassembly (Figure 14). 


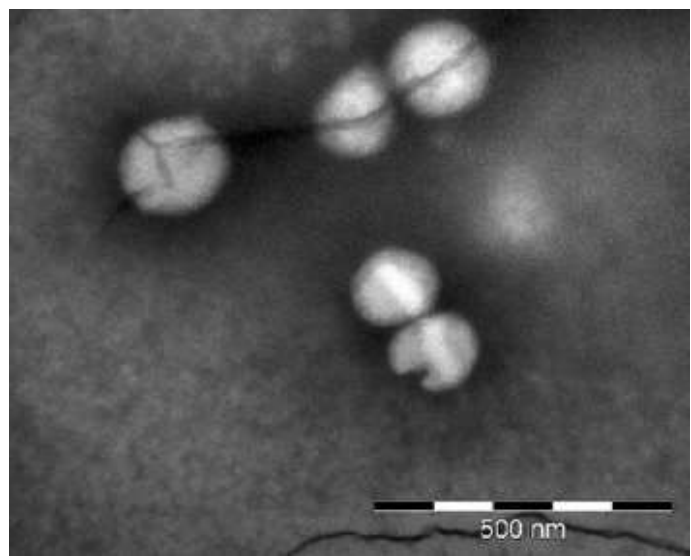

Figure 14. The observed self-assemblies obtained for trans-ACHC oligomers

\subsubsection{Pharmaceutically active $\beta$-peptides}

The search for biological applications of foldamers started shortly after their discovery. Many studies have reported their utility in biology and drug development. Since $\beta$-peptides are able to adopt stable secondary structures, this provides a suitable base for the design of functional mimics of biopolymers, which may interact with biological systems. ${ }^{13}$ An important advantage over the natural peptides and proteins is that $\beta$-peptides are more stable against proteolytic degradation in vivo and in vitro. ${ }^{130-131}$ The naturally occurring $\beta$-amino acid monomer is $\beta$-glycine. It can be found in cryptophycin, a tumour-selective depsipeptide, ${ }^{132}$ and in carnosine, a dipeptide with a strong antioxidant effect found in muscle and other tissues of mammals. ${ }^{133}$ Other, frequent natural monomers are the $\quad \alpha$-hydroxy- $\beta$-amino acids, which are important elements of the cytostaticum taxol. ${ }^{134}$ Some cyclic $\beta$-amino acids can exhibit a strong antibiotic effect, such as

$(1 R, 2 S)-2-$ aminocyclopentanecarboxylic acid: cispentacin, ${ }^{69,70,135}$ BAY 9379 or PLD-118. The last two molecules are under investigation in clinical studies for the treatment of fungal infections. ${ }^{136}$ Pinane-derivative amino acids may be considered as further useful compounds for the development of potential low-toxicity anticonvulsant agents. ${ }^{65}$

$\beta$-Peptides can be applied as peptidomimetics. The change of an $\alpha$-amino acid unit to its $\beta$ derivative in a pharmaceutically active $\alpha$-peptide can enhance its conformational stability. These structurally modified peptides have better bioavailability and can act as potentially active pharmaceutical agents. ${ }^{130,131,137}$ Many instances exist in the literature for this peptidomimetic approach, such as structurally modified angiotensin-II ${ }^{138}$ and gastrin agonists, ${ }^{139}$ an oxytocin- 
analogue peptide ${ }^{140}$ or bombesin receptor antagonists. ${ }^{141,142}$ Incorporation of cyclic $\beta$-amino residues into endomorphine- 2 is also available. ${ }^{143}$

Turn-like secondary structures or cyclic oligomers of the $\beta$-peptides proved excellent skeleton scaffolds for the formation of biologically active foldamers. Structural analogue $\beta$ tetrapeptides of the hormone somatostatin molecule have been designed which display high affinity to the somatostatin sst4-receptor, which prove to have good oral bioavailability and which are also resistant to biodegradation. ${ }^{144,145}$ Cyclic $\beta$-tripeptides have been used as agonists for the CD40 protein receptor, which is a very important member of the TNF-receptor superfamily. The molecules can induce apoptosis in lymphoma and leukaemia cells. ${ }^{146,147}$

\subsubsection{Bioactive $\beta$-peptide helices}

Some $\beta$-peptides show antimicrobial activity and their structures display similar helical amphiphilicity to that of antibacterial $\alpha$-helices, which are importart parts of the innate immune system. These peptides are able to disrupt the bacterial membrane by forming ion channels, collapse the transmembrane potential, link to intracellular objects, and finally cause the death of the bacterium cell. ${ }^{13,148-150}$ Both $\mathrm{H} 14$ helical ${ }^{151-154}$ and $\mathrm{H} 12$ helical antimicrobial $\beta$ peptides ${ }^{155-157}$ have been prepared and their biological activities have been tested on a model bacterium, E. coli. The first series of designed $\beta$-peptides with defined secondary structure were highly potent antimicrobial agents, but they exhibited significant haemolytic activity, damaging human red blood cells, due to their hydrophobic character. ${ }^{149,158}$ Improved selection was achieved with a second series of $\beta$-peptides where the incorporation of positively charged cyclic residues helped to minimize the haemolytic activity, while retaining the high antimicrobial activity. Further $\beta$-peptides with the $\mathrm{H} 12$ helical conformation showed excellent activity against four organisms, including Gram-positive and Gram-negative bacteria. Interestingly, the $\alpha / \beta$ chimera peptides without predefined secondary structures are also known to have significant antibacterial activity with low haemolytic potential. Some $\quad \beta$-peptide H14 helical structures have also been shown to display antifungal activity against Candida albicans cells and are able to inhibit Herpes simplex virus type 1 infection at low micromolar concentrations in cell culture. ${ }^{159-161}$

A major challenge in foldamer research is the modification of protein-protein interactions (PPIs) by using $\beta$-peptidic protein mimetics. Seebach and co-workers reported the first promising designed series of amphiphilic H14 helical $\beta$-peptides intended to mimic the amphipihlic $\alpha$-helices of human apolipoproteins involved in lipid metabolism. These models 
were able to inhibit the absorption of fat and cholesterol. ${ }^{162}$ Active $\beta$-peptides are approximately one-half the length of active $\alpha$-peptides and are resistant to proteolytic degradation. Some polycationic $\beta$-peptides are able to bind to the transcriptional activator-response element (TAR), which is of potential importance in the therapy of HIV. ${ }^{163}$ Polycationic peptides can successfully penetrate cell membranes. For example,

$\beta^{3}$-homoarginine-containing peptides allow efficient membrane transport and crossing the cell membrane with different processes. Homolysine-rich $\beta$-peptides can be used as gene-delivery agents and interact with DNA. ${ }^{164}$ Disruption of the interaction between the tumour suppressor protein p53 and the oncoprotein hDM2 was also achieved with de novo designed $\beta$-peptide sequences. ${ }^{165-168}$ The oncoprotein hDM2 negatively regulates the apoptotic facility of the p53 protein. Elimination of their interaction is a major aim in cancer research. ${ }^{169}$ Since the p53 protein interacts with the hDM2 oncoprotein through an $\alpha$-helix, mimicry with $\beta$-analogue peptides can be practically utilized. The result of the cocrystallization with hDM2 demonstrates a helical geometry similar to the $\alpha$-helix. Interactions between the two domains of the AIDS-related HIVgp41 protein were blocked by $\beta 3$-decapeptide, ${ }^{170,171}$ but inhibition of this protein with $\alpha / \beta$-chimera peptides has also been reported. ${ }^{172}$ Many tumour cells are found to overexpress antiapoptotic protein Bcl$\mathrm{xL}$, the function of which is regulated by proapoptotic factors that bind to Bcl-xL through a BH3 domain. Various designed $\beta$ - and $\quad \alpha / \beta$-chimera sequences are able to act as antagonists for Bcl-xL with significant inhibitory potentials. ${ }^{173,174}$

It has recently been recognized that trans-ACPC-based foldamers with $\mathrm{H} 12$ helical structures can successfully inhibit a specific gamma-secretase and open up a new way in the treatment of Alzheimer's disease. ${ }^{175}$

\subsection{Solid-phase synthesis of $\beta$-peptides}

There are two main solid-phase methodologies for synthesizing $\beta$-peptides. One utilizes tert-butoxycarbonyl/benzyl (Boc/Bzl) ${ }^{176}$ and the other is a 9-fluorenylmethoxycarbonyl/tertbutyl $\left(\mathrm{Fmoc} /{ }^{\mathrm{t}} \mathrm{Bu}\right)$ technique. ${ }^{177}$ The main advantage of these methods as compared with the solution-phase strategy ${ }^{8}$ is that more complex peptidic sequences can be synthesized in a relatively convenient way, although the coupling and deprotection steps require more time than 
that for the analogous steps in the $\alpha$-peptide synthesis. The Boc methodology has been applied successfully for the synthesis of various ACHC- or ACPC-containing oligomers. ${ }^{11}$ Use of the Fmoc chemistry deprotection of protected $\beta$-amino acids is rather difficult (Scheme 1). The use of stronger bases, such as DBU with an elevated deprotection time, leads to incomplete removal of the Fmoc protecting groups. Elevated temperature $\left(60{ }^{\circ} \mathrm{C}\right)$ helps to promote a complete deprotection step, but also increases the tendency to racemization. ${ }^{178}$ In certain cases, completion of the coupling step is difficult for steric reasons. The application of newer coupling reagents such as uronium salts ${ }^{30}$ or microwave-associated coupling conditions ${ }^{178,179}$ can ensure the good-quality final products. The current synthetic protocols mostly apply automated Fmoc solid-phase synthesis.

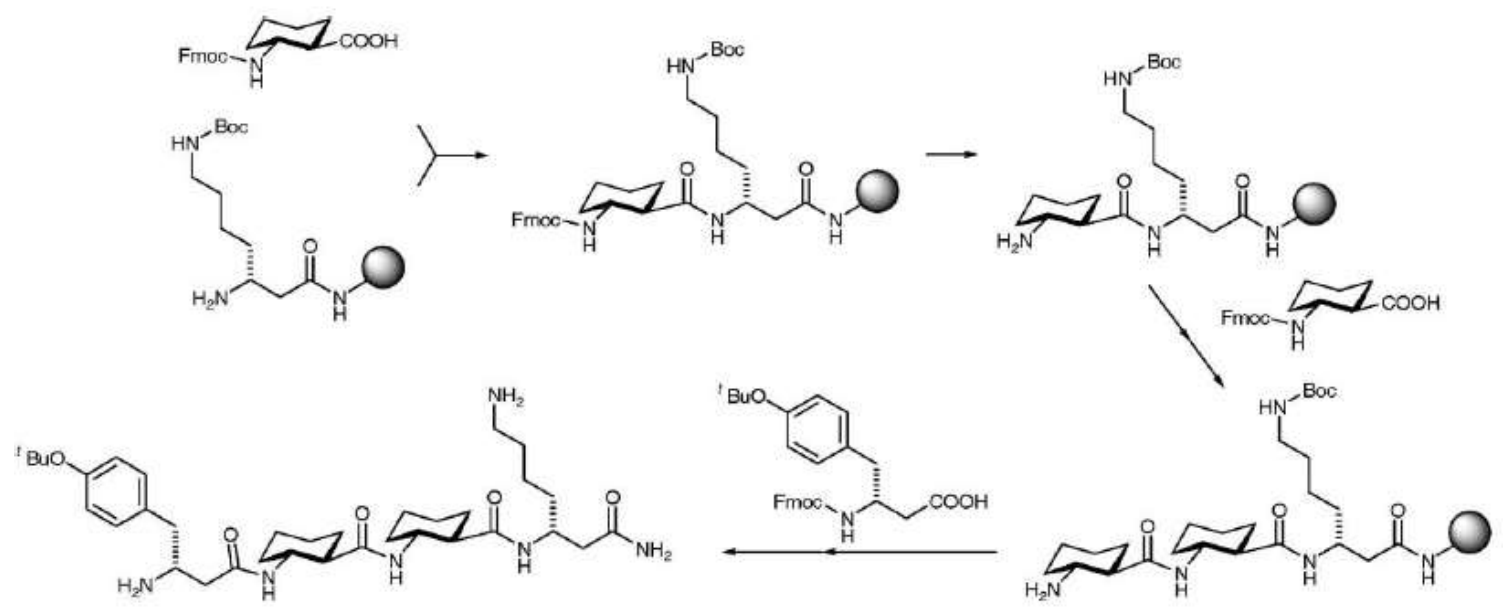

Scheme 1. Basic scheme for Fmoc-based SPPS

\section{Methods}

\subsection{Synthesis}

Peptide Synthesis. All peptides were synthesized on a solid support with Fmoc methodology. The peptide chains were elongated manually on TentaGel R RAM resins $\left(0.17 \mathrm{mmol} \mathrm{g}^{-1}\right.$ or 0.19 
mmol $\left.\mathrm{g}^{-1}\right)^{180}$ with a Rink amide linker on $0.1-0.3 \mathrm{mmol}$ without difficulties. The couplings were performed in two circles. First, 3 equivalents of Fmoc-protected amino acid, 3 equivalents of the uronium coupling agent O-(7-azabenzotriazol-1-yl)-N,N,N',N'-tetramethyluronium hexafluorophosphate (HATU) ${ }^{181}$ and three equivalents of

$\mathrm{N}, \mathrm{N}$-diisopropylethylamine (DIPEA) were used in N,N-dimethylformamide (DMF) as solvent, with shaking for 3 - $4 \mathrm{~h}$. In the second step, each coupling was repeated with 1 equivalent of the same materials. Between the couplings, the resin was washed three times with DCM, once with $\mathrm{MeOH}$ and three times with DCM. The incorporation of the amino acids was monitored by means of the ninhydrin test. ${ }^{182}$ To avoid truncated sequences, cleavages of the aliquots from the resin were performed with the growing chain-length. The Fmoc group was removed by using 2\% 1,8diazabicycloundec-7-ene (DBU) and 2\% piperidine in DMF, with reaction times of 5 and 15 min. After the deprotection step, the resin was washed with the same solvents as described previously. Finally, the peptides were detached from the resin with $95 \%$ TFA $+5 \% \mathrm{H}_{2} \mathrm{O}$ solution at $25{ }^{\circ} \mathrm{C}$ for $3 \mathrm{~h}$. The TFA was removed and the resulting free peptides were precipitated with cooled dried diethyl ether. The precipitated peptides were filtered off, washed and then solubilized in $10 \%$ aqueous acetic acid, diluted with water and lyophilized. The crude peptides were identified by reverse-phase HPLC, using Phenomenex C18 and C4 columns (4.6 X $250 \mathrm{~mm}) .{ }^{183}$ The applied solvent system was as follows: TFA $(0.1 \%)$ in water (A), TFA $(0.1 \%)$ and acetonitrile $(80 \%)$ in water $(\mathrm{B})$; gradients were: $0 \% \rightarrow 50 \%$ B during 15 min, then $50 \% \rightarrow 80 \%$ during $60 \mathrm{~min}$, at a flow rate of $4 \mathrm{~mL} \mathrm{~min}^{-1}$ and $5 \% \rightarrow 100 \% \mathrm{~B}$ during $35 \mathrm{~min}$, with a flow rate of $1.2 \mathrm{~mL} \mathrm{~min}^{-1}$, and detection at $206 \mathrm{~nm}$. The peptides were purified on Phenomenex C18 and C4 (4.6 x $250 \mathrm{~mm})$ columns. ${ }^{183}$ The HPLC instrument was made by JASCO. ${ }^{184}$ The appropriate pure fractions were pooled and lyophilized. The purified peptides were characterized by mass spectrometry (MS), using a Finnigan MAT 95S sector field mass spectrometer ${ }^{185}$ equipped with an electrospray ion source and an Agilent 1100 LC-MSD trap mass spectrometer ${ }^{186}$ equipped with an electrospray ion source.

\subsection{Structure investigations}

Nuclear magnetic resonance (NMR) measurements were carried out on a Bruker Avance III $600 \mathrm{MHz}$ spectrometer ${ }^{187}$ with a multinuclear probe. The signal assignments were performed with the help of two-dimensional (2D) NMR techniques. The ROESY ${ }^{188}$ measurements were carried out with the WATERGATE solvent suppression scheme. For the ROESY spinlock, mixing times of 225 and $400 \mathrm{~ms}$ were used; the number of scans was 64. The TOCSY ${ }^{189-190}$ 
measurements were performed with homonuclear Hartman-Hahn transfer with the MLEV17 sequence, with a mixing time of $80 \mathrm{~ms}$, the number of scans being 32. For all the 2D spectra, 2024 time domain points and 512 increments were applied. The processing was carried out by using a cosine-bell window function; with single zero filling and automatic baseline correction Electronic circular dichroism (ECD) measurements were carried out on both a Jobin-Yvon Mark VI dichrograph and a Jasco J815 spectometer ${ }^{191}$ at $25^{\circ} \mathrm{C}$ in a $0.02 \mathrm{~cm}$ cell. Four spectra were accumulated for each sample. The baseline spectra recorded with only the solvent were subtracted from the raw data. The concentration of the samples was between 1 and $4 \mathrm{mM}$ in $\mathrm{MeOH}$. Molar ellipticity, $[\Theta]$, is given in $\operatorname{deg} \mathrm{cm}^{2} \mathrm{dmol}^{-1}$. The data were normalized for the oligomer concentration and the number of chromophores. For spectrum interpretation, Spectra Manager $2.0^{192}$ software was used.

FT-IR measurements were set on a Pelkin-Elmer Spectrum 100 instrument. ${ }^{193}$ Microanalyses were performed on a Pelkin-Elmer 2400 elemental analyser. ${ }^{193}$

UV measurements were carried out on a UV-1800 spectrometer in the range 190-250 nm in cells with an optical path of $1 \mathrm{~cm}$. The data obtained were exported in text files. The correlation coefficients were determined by numerical analyses of the raw spectral data.

Molecular mechanical simulations were performed on the Molecular Operating Environment (MOE) software ${ }^{194}$ of the Chemical Computing Group. For the energy calculations, the MMFF94x ${ }^{195,196}$ force field was used, without cut-off for van der Waals and Coulomb interactions, and the distance-dependent dielectric constant $\left(\varepsilon_{\mathrm{r}}\right)$ was set to $\varepsilon=1.8$ (corresponding to $\mathrm{MeOH}$ ). The conformational sampling was carried out by using the hybrid Monte Carlo (MC) - molecular dynamics (MD) simulation (as implemented in MOE) at 300 $\mathrm{K}$, with a random MC sampling step after every $10 \mathrm{MD}$ steps. The MC-MD simulation was run with a step size of 2 fs for $20 \mathrm{~ns}$ and the conformations were saved after every 1000 MD steps, which resulted in $10^{4}$ structures. For the NMR restrained simulation, the upper distance limits were calculated by using the isolated spin pair approximation and classified by following the standard method (strong $2.5 \AA$, medium $3.5 \AA$ and weak $5 \AA$ ). The lower limit was set to $1.8 \AA$. Restraints were applied as a flat-bottomed quadratic penalty term with a force constant of 5 or $10 \mathrm{kcal} / \AA$. The final conformations were minimized to a gradient of $0.05 \mathrm{kcal} / \mathrm{mol}$ and the minimization was applied in a cascade manner, using the steepest-descent, conjugate gradient and the truncated Newton algorithm.

Ab initio optimizations were carried out in two steps with the suitable version of the Gaussian program $^{197}$ : first by using the HF/3-21G basis set and then by using density-functional theory at the B3LYP/6-311G** level with a default setup. 


\subsection{Aggregation-related measurements}

DOSY (PFGSE) NMR measurements ${ }^{198}$ were run by using the stimulated echo and longitudinal eddy current delay (LED) sequence with water suppression. A time of 2 ms was used for the dephasing/refocusing gradient pulse length $(\delta)$ and $250 \mathrm{~ms}$ for the diffusion delay $(\Delta)$. The gradient strength was changed quadratically from $5 \%$ to $95 \%$ of the maximum value (10 A gradient amplifier) and the number of scans was 16 or 32. Each measurement was run with 64 or 256 scans and $2 \mathrm{~K}$ time domain points. For the processing, an exponential window function and single zero filling were applied. During the diffusion measurements, the fluctuation of the temperature was less than $0.1 \mathrm{~K}$. Prior to the NMR scans, all the samples were equilibrated for $30 \mathrm{~min}$. DOSY spectra were processed and evaluated by using the exponential fit implemented in a suitable version of Topspin. The aggregation numbers were calculated from the Stokes-Einstein equation and an external volume standard was utilized.

Concentration-dependent ECD measurements were also made with the Jasco J815 spectrometer ${ }^{191}$ at room temperature in a $0.02 \mathrm{~cm}$ quartz cell. The concentration of the sample solution series was $25 \mu \mathrm{M}-1 \mathrm{mM}$ in $\mathrm{MeOH}$. Ten spectra were accumulated for each sample. Molar ellipticity, $[\Theta]$, is given in $\operatorname{deg} \mathrm{cm}^{2} \mathrm{dmol}^{-1}$. The data were normalized for the oligomer concentration and the number of chromophores.

\section{Results and discussion}

\subsection{Sculpting the $\beta$-peptide H12 helix via bicyclic side-chains}

The stabilization effects of $\beta$-amino acid residues containing cyclic side-chains are very important in the design of $\beta$-peptide helices. The H12 helix is an excellent mimic of the $\alpha$-helix, and it can be achieved with incorporation of a sufficient number of alicyclic trans-2aminocyclopentanecarboxylic acids (trans-ACPC) or its heteroatom-containing analogues, the trans-4-amino pyrrolidine-3-carboxylic acid (trans-ACP) monomers in the sequence. To gain 
stable H12 helical structure, two-thirds of the residues are needed to have the side-chain topology of a five-membered ring with trans relative backbone configuration.

Our major aim was to find a novel approach for stabilizing the H12 helix. Construction of the H14 helix, the most often utilized secondary structure in biomedical applications, can be stabilized by using open-chain $\beta^{3}$-substituted $\beta$-amino acids and/or with the six-membered ringcontaining trans-2-aminocyclohexanecarboxylic acid residues (trans-ACHCs). The cyclic sidechains provide extra stability to the structure via the restricted conformational space and the $(i)$ $-(i+3)$ hydrophobic stacking interactions between the cyclohexane rings. Successful synthesis allowed the formation of monoterpene-derived $\beta$-amino acid monomers with an apopinane skeleton (2-amino-6,6-dimethyl-bicyclo[3.3.1] heptane-3-carboxylic acid; trans-ABHC), which is the bicyclic analogue of ACHC. ${ }^{199}$ The substitution of the ACHC residues with these bulky monomers predicts steric repulsions between the side-chains in positions $(i)$ and $(i+3)$ instead of the $(i)-(i+3)$ hydrophobic stacking interactions (Figure 15).

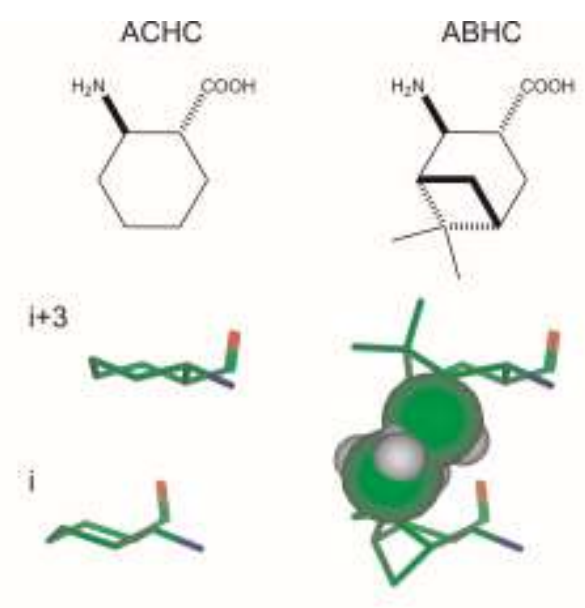

Figure 15. Stacking and repulsive interactions between the different sidechains in positions $(i)-(i+3)$

To test the effect of the $(i)-(i+3)$ steric clash on the preferred secondary structure, homo-oligomers containing trans-ABHC residues were designed with different chain-lengths. Conformational sampling was carried out on the hexamer by using a hybrid molecular dynamics (MD) - Monte (MC) method and MMFF94x ${ }^{195,196}$ force field. The results showed some regular helical fold. The lowest energy conformational family was the H12 helix $\quad(32 \%)$ of the conformers, average cluster energy relative to the lowest energy conformation: $18.55 \mathrm{~kJ} / \mathrm{mol}$. Interestingly, the H16 helix type fold was also found, but with higher conformational energies $\left(21 \%, 74.32 \mathrm{~kJ} \mathrm{~mol}^{-1}\right)$. The H14 helix was only a low-population high-energy cluster $(0.3 \%$, 
$\left.138.37 \mathrm{~kJ} \mathrm{~mol}^{-1}\right)$. Helical structures with a combination of rings were identified in $22 \%$ of the conformers (Figure 16).

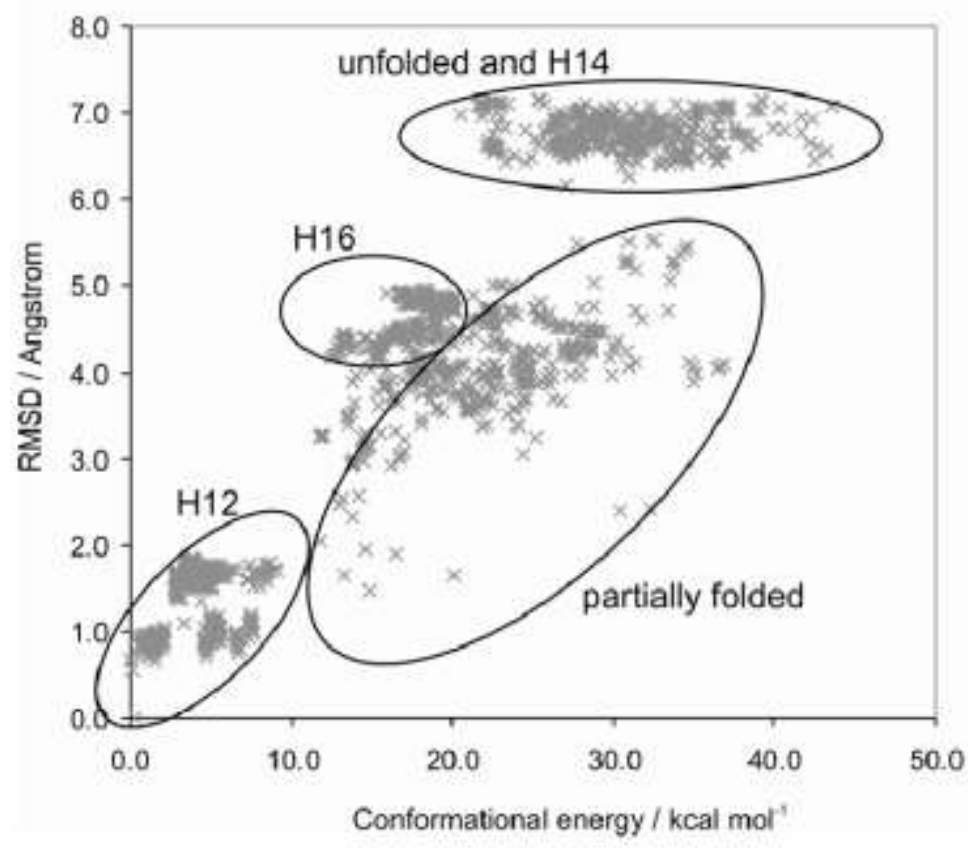

Figure 16. Cluster analysis of the unrestrained conformational sampling for 4 conformers) carried out by using MMFF94 ${ }^{195,196}$ force-field and the hybrid MD-MC algorithm. RMSD was calculated with the lowest energy $\mathrm{H} 12$ helix conformer as the reference structure. The conformational energies are referenced to the lowest energy conformer.

All the geometrically possible helices for each oligomer H8, H10, H12, H14 and H16 were optimized at the $a b$ initio quantum chemical level ${ }^{197}$ too (Figure 17).

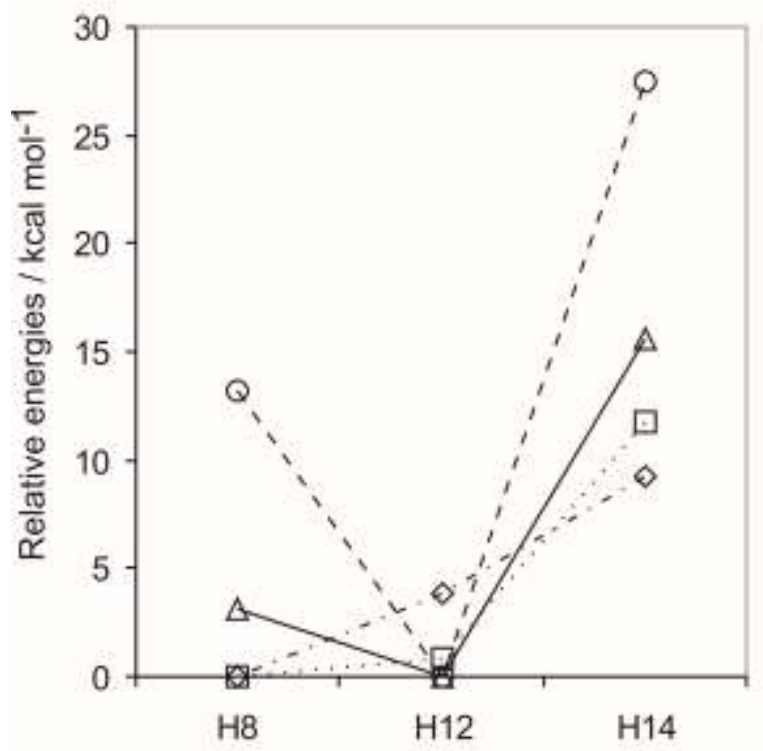


Figure 17. Relative B3LYP/6-311G** energies (actual energy - lowest energy) of 1-4 for the $a b$ initio calculated helical secondary structures

The HF/3-21G//B3LYP/6-311G** levels of theory in vacuo were utilized, as these have been reported to provide a good approximation for the $\beta$-peptides. ${ }^{200,201}$ The structures converged to the corresponding local minimum of the potential energy surface, except for the H10 helices, which finally converged to H14. The modelling indicated that H12 or H16 is the most likely secondary structure for the longer oligomers. For the shorter structures, H8 is a low energy fold too. These findings strongly supported the side-chain repulsion for shaping the desired secondary structure.

Model compounds 1-4 were synthesized (Scheme 2). The Fmoc-( $1 R, 2 R, 3 R, 5 R)$-ABHC stereoisomer was prepared according to a literature method. ${ }^{199}$ The chain assemblies were carried out on a solid support, utilizing Fmoc methodology. The final products were characterized by means of MS and various NMR methods, including COSY, TOCSY and ROESY, in $4 \mathrm{mM} \mathrm{CD} 3 \mathrm{OH}$ and $\left[\mathrm{D}_{6}\right] \mathrm{DMSO}$. In water, severe solubility problems were experienced. The NMR signal dispersions were very good and resonance broadening was not detected, and complete resonance assignment was therefore achievable along the backbone.

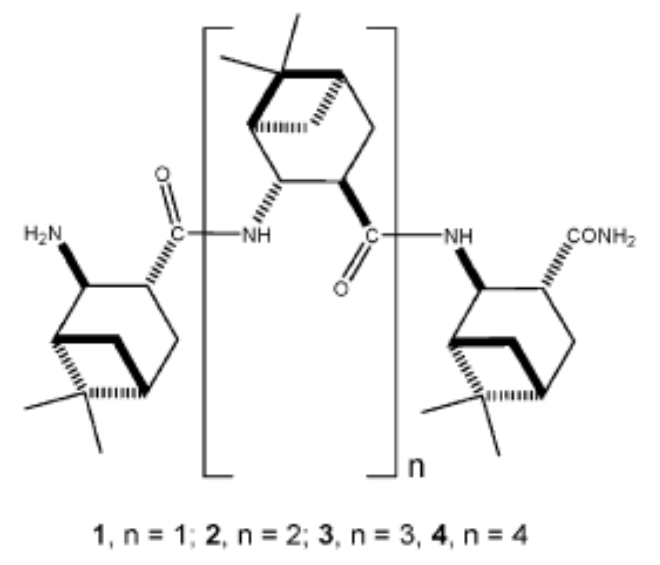

Scheme 2. The structures studied

A ROESY experiment on 4 unambiguously proved the H12 helical conformation in [D6]DMSO, because the characteristic $\mathrm{C}^{\beta} \mathrm{H}_{\mathrm{i}}-\mathrm{C}^{\alpha} \mathrm{H}_{\mathrm{i}+2}, \mathrm{C}^{\beta} \mathrm{H}_{\mathrm{i}}-\mathrm{NH}_{\mathrm{i}+2}$ and $\mathrm{Me}_{\mathrm{i}}-\mathrm{NH}_{\mathrm{i}+3}$ long-range NOE interactions could readily be observed (Figure 18). 


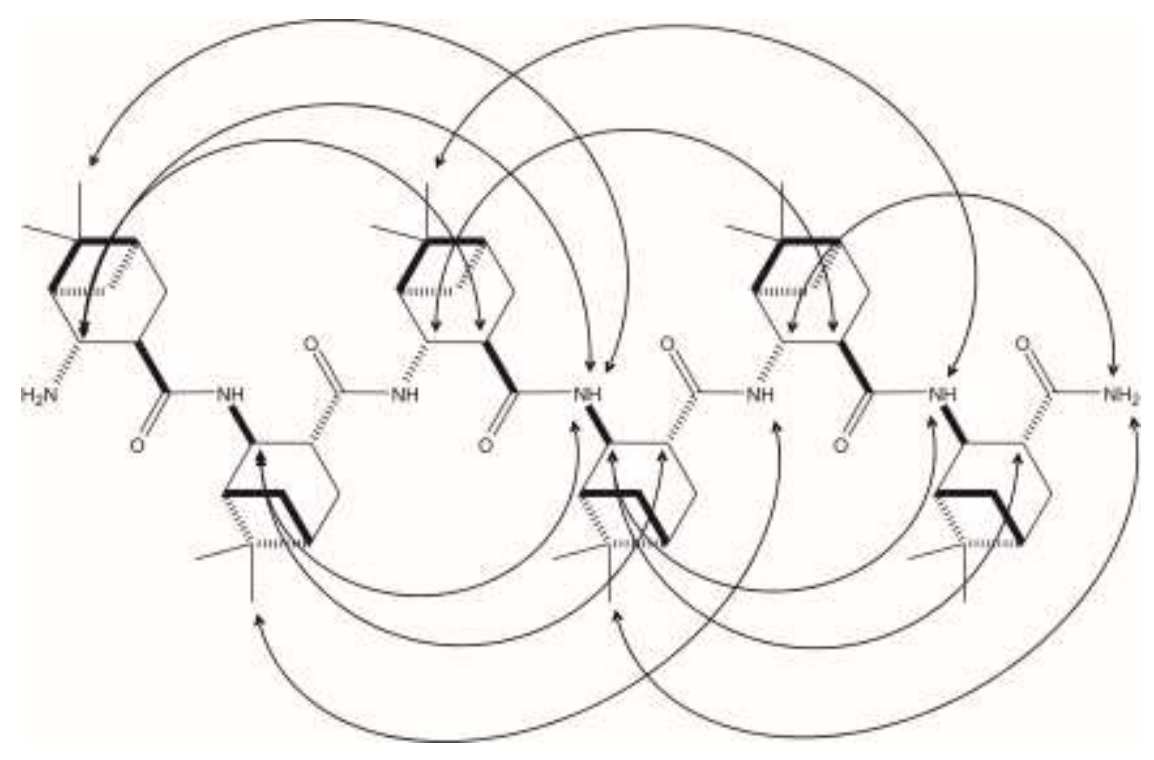

Figure 18. Resolvable long-range NOE interactions detected in the ROESY spectrum of 4 in [D6]DMSO

Hybrid MD-MC modelling with NMR restraints for $\mathbf{4}$ exclusively resulted in the H12 helix, ruling out any unfolded structures or other helix types as a predominant conformation (Figure 19). The NOEs between the axial Me groups and amide protons are only due to the H12 helix. A sufficient number of characteristic NOEs were observed in $\mathrm{CD}_{3} \mathrm{OH}$; some of the longrange ROESY cross-peaks could not be resolved because of the poorer resonance dispersion for the $\mathrm{C}^{\beta} \mathrm{H}_{2-4}$ protons. The $\mathrm{C}^{\beta} \mathrm{H}_{1}-\mathrm{NH}_{3}$ interaction was not observed, but a weak $\mathrm{C}^{\beta} \mathrm{H}_{1}-\mathrm{NH}_{4}$ cross-peak was detected in both solvents, which is in agreement with the H12 helix. For $\mathbf{3}$, the H12 helix long-range NOE interactions could also be observed, but $\mathbf{2}$ and $\mathbf{1}$ did not exhibit any helix-related signal.

a

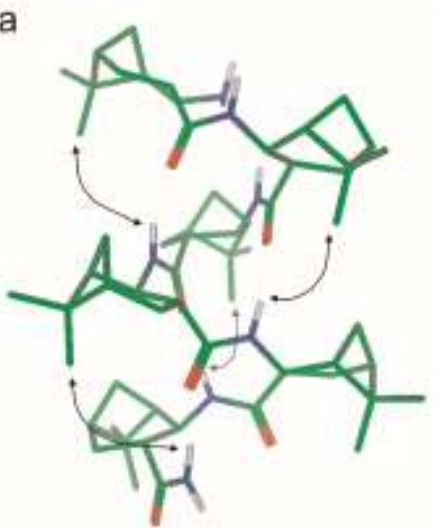

b

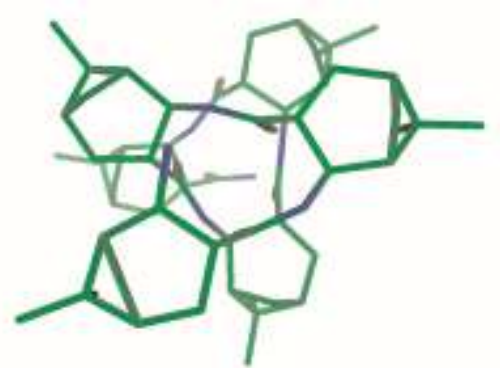


Figure 19. Side view (a) and top view (b) of the NMR-derived H12 helix formed by 4. Arrows indicate the very characteristic $\mathrm{Me}_{\mathrm{i}}-\mathrm{NH}-\mathrm{i}+3$ NOEs observed in the ROESY spectrum of 4 (see Fig. 19)

ECD measurements were carried out to gain evidence for the presence of the helical fold. Measurements were carried out only in $\mathrm{MeOH}$ as the ECD spectra in DMSO are not useful for the secondary structure investigation of peptides and proteins because of the interfering absorption from the solvent below $268 \mathrm{~nm}$. In water, solubility problems were detected which prevented the measurement. The direct comparison with the literature ECD fingerprints obtained for various UV inactive side-chains is not possible because of the extreme sensitivity of the ECD to small changes in the foldamer geometry ${ }^{202}$ and of the UV absorbance of the asymmetric cyclobutane moiety in the range 190-250 nm. ${ }^{203,204}$ Furthermore, CD results have not been published for a $\beta$-peptide helix with a cyclobutane fragment in the side-chain. ${ }^{205}$ The spectra revealed a significant chain-length dependence (Figure 20). The positive lobes display a maximum at around $220 \mathrm{~nm}$ for $\mathbf{1}$ and $\mathbf{2}$, while the band is shifted to $210 \mathrm{~nm}$ and 205 $\mathrm{nm}$ for $\mathbf{3}$ and $\mathbf{4}$, respectively. The position of the negative band remains constant at around 195 $\mathrm{nm}$. An essential feature of the helix formation is that the folding takes place in a chain lengthdependent manner which is unambiguously indicated by the continuous hypsochromic displacement of the positive band and the increasing symmetry of the positive couplet. Peptides $\mathbf{2}$ and $\mathbf{3}$ display higher intensities at short wavelengths, which might indicate a partial population of an elongated structure such as the H8 helix. ${ }^{107,108}$

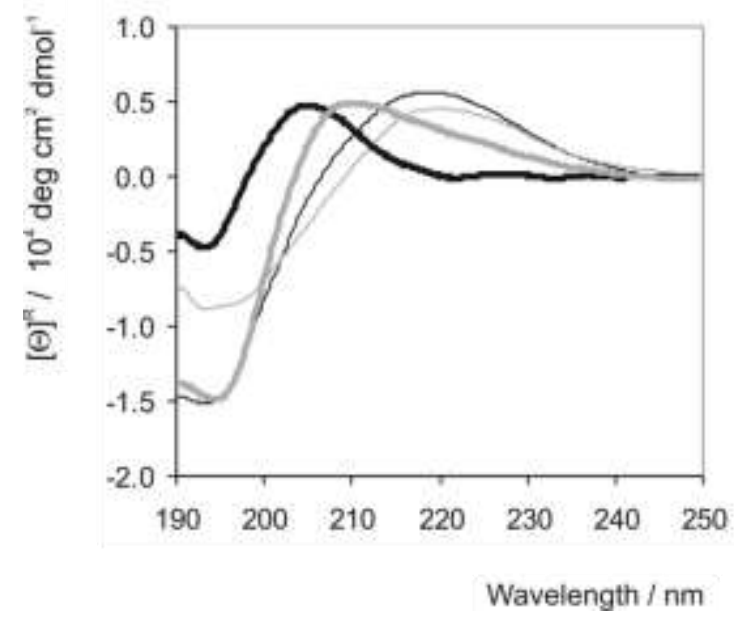

Figure 20. ECD curves measured for 1 (thin grey), 2 (thin black), 3 (thick grey) and $\mathbf{4}$ (thick black)

The time dependence of the residual NH signal intensities in the $\mathrm{H}^{1} \mathrm{~N}-\mathrm{N}^{2} \mathrm{D}$ exchange experiments for $\mathbf{4}$ point to the corresponding atoms being considerably shielded from the 
solvent, due to hydrogen-bonding interactions. The proton resonances of the terminal amine and the C-terminal amide disappeared immediately after the dissolution, but the other signals remained for a longer time. The observed exchange pattern was in good agreement with the hydrogen-bonding network of the H12 helix. For 3, a similar exchange pattern was detected, but the exchange rates were higher, suggesting a less-ordered structure (Figure 21).

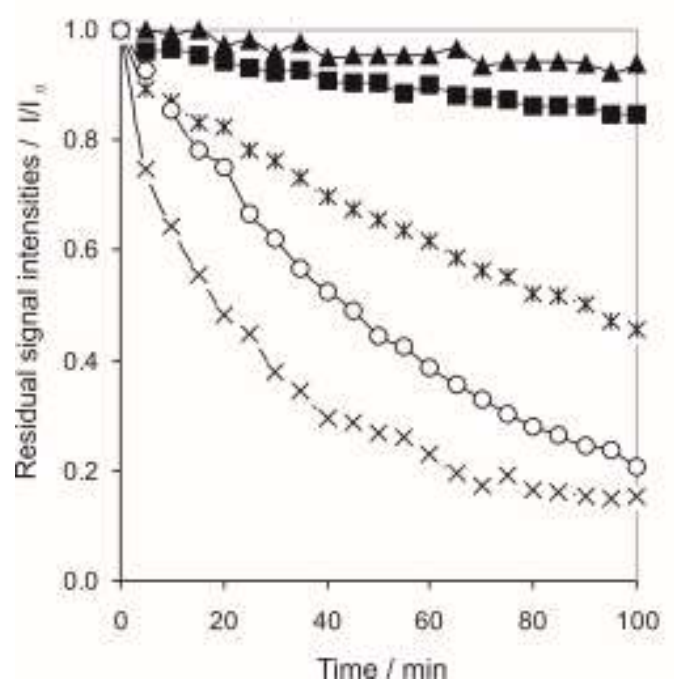

Figure 21. Time dependence of $\mathrm{NH} / \mathrm{ND}$ exchange for 4 in $\mathrm{CD}_{3} \mathrm{OD} \quad(*$ : $\mathrm{NH} 2 ; \circ: \mathrm{NH} 3 ; \boldsymbol{\Delta}$ : $\mathrm{NH} 4 ; \mathbf{a}: \mathrm{NH} 5 ; \mathrm{x}$ : NH6)

Scalar couplings measured on the amide protons of $\mathbf{3}$ and $\mathbf{4}$ indicated values well above $8.5 \mathrm{~Hz}$ in [ $\left.\mathrm{D}_{6}\right] \mathrm{DMSO}$, except for the $\mathrm{N}$-terminal residues, which is in line with the antiperiplanar $\mathrm{NH}-\mathrm{C}^{\beta} \mathrm{H}$ orientation necessary for the helical structure. For $\mathbf{2}$, the couplings were significantly decreased, but indicate a prevailing antiperiplanar arrangement for the non-terminal residues, while 1 exhibits couplings pointing to random $\mathrm{NH}-\mathrm{C}^{\beta} \mathrm{H}_{\mathrm{i}}$ dihedrals. In $\mathrm{CD}_{3} \mathrm{OH}$, a similar coupling pattern was found (Table 1).

Table 1. ${ }^{3} J\left(\mathrm{NH}_{\mathrm{i}}-\mathrm{C}^{\beta} \mathrm{H}_{\mathrm{i}}\right)$ values in $\left[\mathrm{D}_{6}\right] \mathrm{DMSO}$ and $\mathrm{CD}_{3} \mathrm{OH}$ 


\begin{tabular}{|c|c|c|c|c|}
\hline$i$ & 1 & 2 & 3 & 4 \\
\hline 2 & 7.40 & 7.48 & 7.25 & 7.03 \\
\hline 3 & 8.07 & 8.71 & 8.50 & 8.55 \\
\hline 4 & - & 8.88 & 9.45 & 9.07 \\
\hline 5 & - & - & 9.25 & 9.50 \\
\hline 6 & - & - & $\cdot$ & 9.25 \\
\hline \multicolumn{5}{|c|}{$\mathrm{CD}_{3} \mathrm{OH}$} \\
\hline$i$ & 1 & 2 & 3 & 4 \\
\hline 2 & 7.20 & 7.98 & 7.73 & 6.83 \\
\hline 3 & 7.90 & 8.38 & 8.07 & 7.82 \\
\hline 4 & - & 8.26 & 9.06 & 8.68 \\
\hline 5 & - & - & 9.10 & 9,23 \\
\hline 6 & - & - & - & 9.04 \\
\hline
\end{tabular}

Experimental $^{206-210}$ and theoretical ${ }^{211}$ studies demonstrated that self-association in the solution phase is an inherent feature of the horizontally or vertically amphiphilic $\beta$-peptide foldamers. ${ }^{113,129}$ To test this phenomenon on our peptides, DOSY NMR measurements were run and the aggregation numbers were determined in $\mathrm{CD}_{3} \mathrm{OD}$ from the measured diffusion constants for 3 and $\mathbf{4}$ in the described manner ${ }^{118}$ (Table 2). In the present work, glucose was utilized as an external reference. The average aggregation numbers were 8.6 and 13.9, respectively. Since no head-to-tail NOE was detected for these peptides, the side-by-side helix association type is likely. These results revealed that the $\mathrm{H} 12$ helix constructed from the trans$\mathrm{ABHC}$ residues is capable of self-association, which is in good agreement with the slowness of the NH/ND exchange due to the extra shielding.

Table 2. Aggregation numbers in $\mathrm{CD}_{3} \mathrm{OD}$, based on DOSY NMR measurements.

\begin{tabular}{|c|c|c|c|c|c|}
\hline & $\begin{array}{l}\text { Calculated } \\
\text { volume }\end{array}$ & $\begin{array}{l}\text { Calculated } \\
\text { radius }\end{array}$ & $\begin{array}{l}\text { Diffusion } \\
\text { constant }\end{array}$ & $\begin{array}{l}\text { Measured } \\
\text { radius }\end{array}$ & $\begin{array}{l}\text { Aggregation } \\
\text { number }\end{array}$ \\
\hline Compound & $\mathrm{A}^{3}$ & $\mathrm{~A}$ & $\mathrm{x} 10^{-9} \mathrm{~m}^{2} \mathrm{~s}^{-1}$ & A & \\
\hline glucose & 506.83 & 4.95 & 2.08 & ${ }^{6}$ & 1 \\
\hline 3 & 2140.14 & 7.99 & 0.63 & 16.4 & 8.6 \\
\hline 4 & 2513.36 & 8.43 & 0.51 & 20.3 & 13.9 \\
\hline
\end{tabular}

\subsection{Self-association-driven large-diameter helix formation}

We have demonstrated that homo-oligomers of the apopinane-based $(1 R, 2 R, 3 R, 5 R)$ trans-ABHC ${ }^{199}$ are able to stabilize the $\mathrm{H} 12$ helix. It is also known from the literature, that increase of the chainlength can result in larger-diameter helices, such as chain lengthdependent helix $\rightarrow$ helix transitions. ${ }^{22-30}$ To test the presence of a possible conformational polymorphism, various patterns of oligomers containing (1S,2S,3S,5S)-2-amino-6,6dimethylbicyclo[3.3.1] heptane-3-carboxylic acid (trans-ABHC) and $\beta^{3}$-hSer residues were 
designed and synthesized in the heptamer-nonamer range (Scheme 3); thereby the tolerance of open-chain residues $^{212}$ for the bicyclic residue-based $\mathrm{H} 12$ helix was also determined.
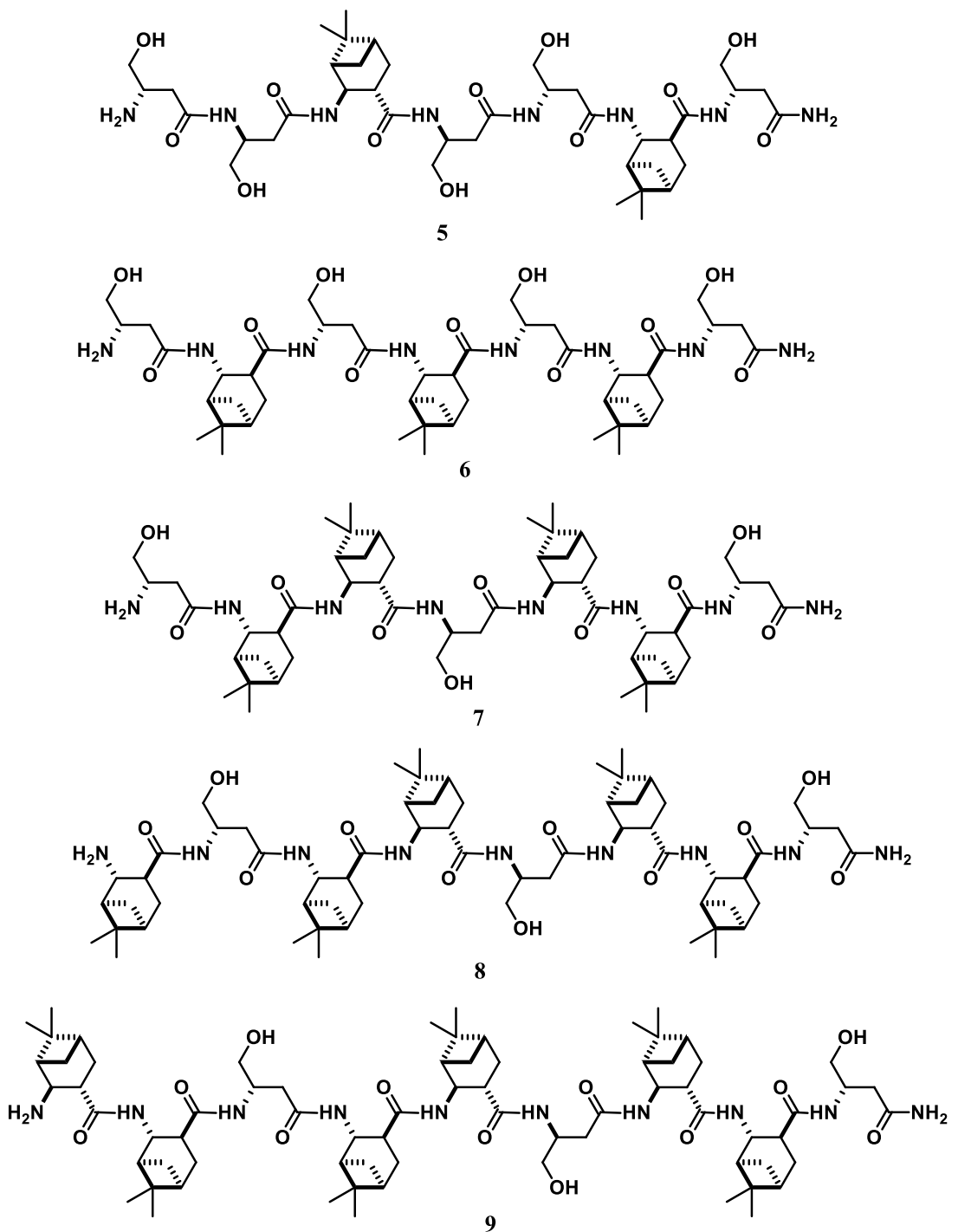

Scheme 3. The studied trans-ABHC-containing structures

As regards the poor solubility of the pure-ABHC chains, the aim of the insertion of the hydrophilic $\beta^{3}$-hSer residues was to avoid the application of any charged side-chains that could potentially lead to salt-bridge interactions, and hence allow steric influences to work on the preferred conformation.

The sequences were synthesized on a solid support, with Fmoc chemistry. Because of the hydrophobic bulky residues, these peptides were in general not water-soluble.

ECD spectra were recorded in methanol at a peptide concentration of $1 \mathrm{mM}$. The foldamers displayed marked differences in their ECD fingerprints. The minimum near $215 \mathrm{~nm}$ 
and a maximum near $195 \mathrm{~nm}$ indicated the $\mathrm{H} 14$ helical structure with a left-handed $(M)$ overall helicity for 5. The lower-intensity negative Cotton effect observed for $\mathbf{6}$ suggested a partial folding into the H14 helix. For 7, a positive Cotton effect with a high-wavelength lobe at around $220 \mathrm{~nm}$ was observed, which is characteristic of a $\mathrm{H} 12$ helix with a right-handed helicity $(P)$. Peptides $\mathbf{8}$ and $\mathbf{9}$ again exhibited a negative Cotton effect, but the positive lobes were missing relative to 7, while the negative lobe remained under $210 \mathrm{~nm}$. All these facts indicated that 8 and 9 have opposite helicity as compared with that of 7 . The change in helicity could again be explained by the formation of left-handed $(M) \mathrm{H} 14$ helices, but this is unlikely because of the growing number of ABHC-ABHC $(i)-(i+3)$ repulsions. The ECD findings therefore supported the appearance of a new helical structure with a left-handed $(M)$ helicity in $\mathrm{MeOH}$ for the longer $\mathbf{8}$ and $\mathbf{9}$ sequences.

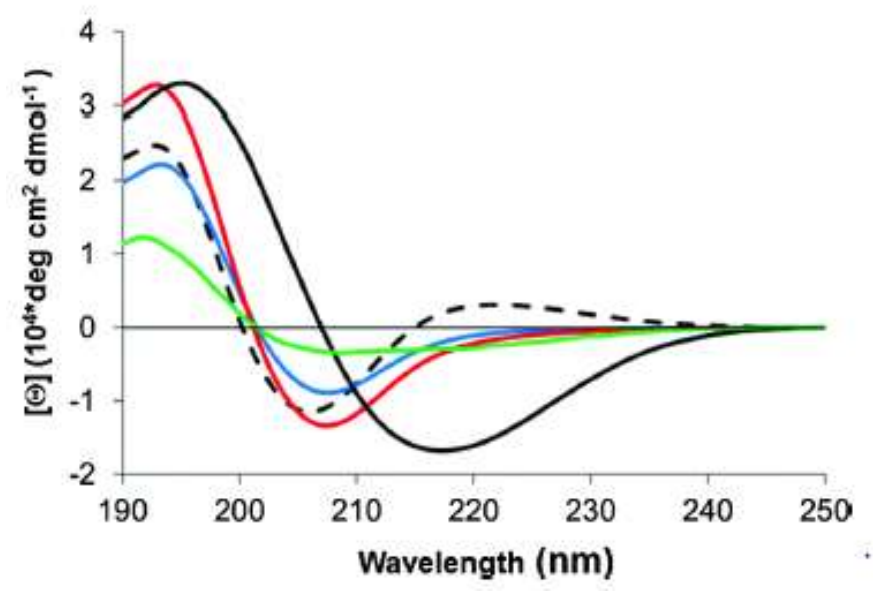

Figure 22. ECD curves measured for 5 (black), 6 (green), 7 (dashed), 8 (blue) and 9 (red) in $\mathrm{MeOH}$ at a concentration of $1 \mathrm{mM}$

To gain high-resolution structural data, various NMR measurements were carried out. The signal dispersions were good enough to allow complete ${ }^{1} \mathrm{H}-\mathrm{NMR}$ assignments along the backbone with the help of various 2D techniques including TOCSY and ROESY measurements. ROESY experiments were run in $\mathrm{CD}_{3} \mathrm{OH}$ and [ $\mathrm{D}_{6}$ ]DMSO. Signal-rich ROESY

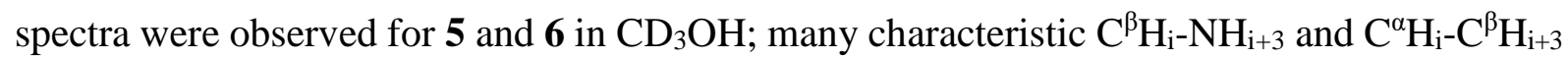
long-range NOE interactions supported the H14 helix (Figure 23). A single $\mathrm{C}^{\alpha} \mathrm{H}_{\mathrm{i}}-\mathrm{C}^{\beta} \mathrm{H}_{\mathrm{i}+2}$ longrange NOE interaction was found for $\mathbf{6}$, indicating its less stable H14 helical conformation. The ROESY spectra recorded in $\left[\mathrm{D}_{6}\right] \mathrm{DMSO}$ were signal-poor for $\mathbf{5}$ and $\mathbf{6}$, indicating that the chaotropic solvent was able to unfold the H14 helix. 

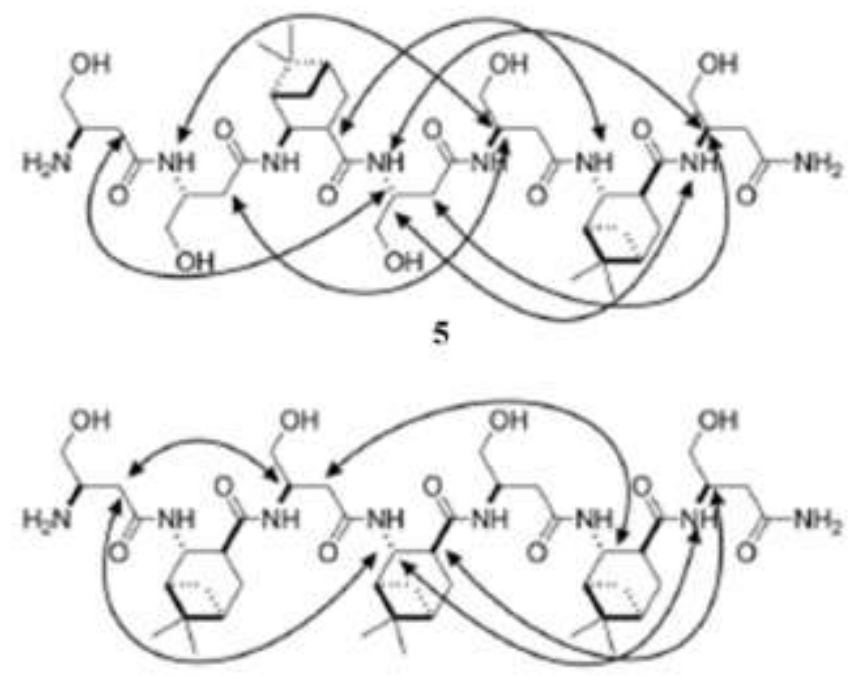

6

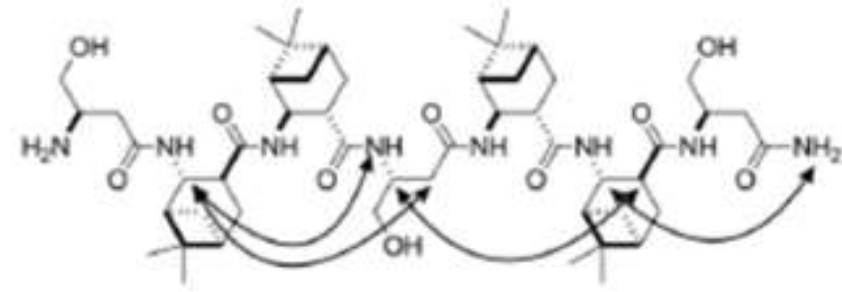

7

Figure 23. Long-range interactions observed for 5-7 in $\mathrm{CD}_{3} \mathrm{OH}$

On the other hand, numerous $\mathrm{C}^{\beta} \mathrm{H}_{\mathrm{i}}-\mathrm{NH}_{\mathrm{i}+2}$ and $\mathrm{C}^{\beta} \mathrm{H}_{\mathrm{i}}-\mathrm{C}^{\alpha} \mathrm{H}_{\mathrm{i}+2} \mathrm{NOE}$ interactions were identified, both in $\mathrm{CD}_{3} \mathrm{OH}$ and in $\left[\mathrm{D}_{6}\right] \mathrm{DMSO}$, and contacts between the axial Me groups and the amide protons $\left(\mathrm{Me}_{\mathrm{i}}-\mathrm{NH}_{\mathrm{i}+3}\right)$ were further observed for $\mathbf{7}$, indicating the formation of the wellfolded right-handed $(P) \mathrm{H} 12$ helix (Figure 24). This helical conformation was supported by structure refinement calculations and scalar coupling data as well. The NMR results were in line with the ECD findings.

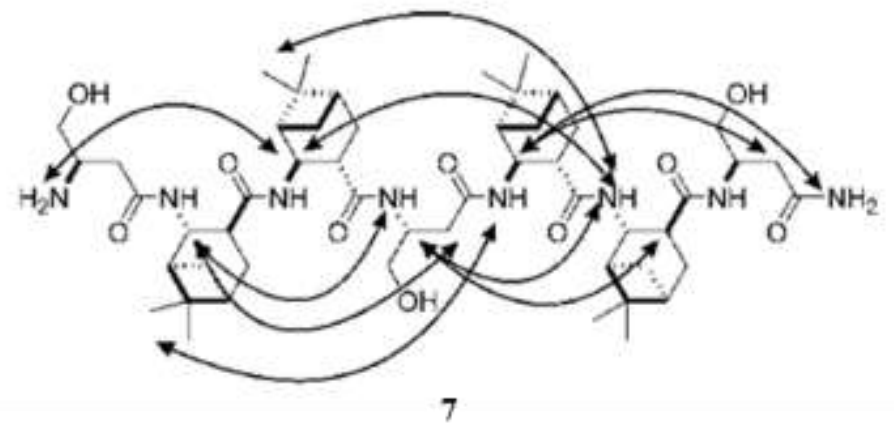

Figure 24. The observed NOE interactions for 7 in $\left[\mathrm{D}_{6}\right] \mathrm{DMSO}$ 
We can conclude from these results that the presence of at least two ABHC - ABHC pairs in the $(i)-(i+3)$ positions is necessary to guide the system successfully into the H12 helix for these heptameric sequences.

Interestingly, the NOE patterns observed for $\mathbf{8}$ and $\mathbf{9}$ were solvent-dependent. While the known $\mathrm{C}^{\beta} \mathrm{H}_{\mathrm{i}}-\mathrm{C}^{\alpha} \mathrm{H}_{\mathrm{i}+2}$ interactions were found, which is indicative of the $\mathrm{H} 12$ helix in [D $]$ DMSO, previously unreported $\mathrm{NOE}$ patterns appeared in $\mathrm{CD}_{3} \mathrm{OH}$. Long-range NOE interactions arising

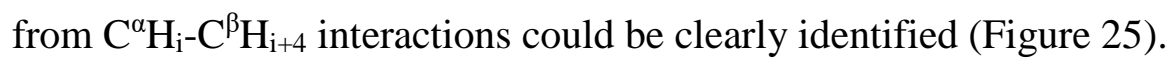

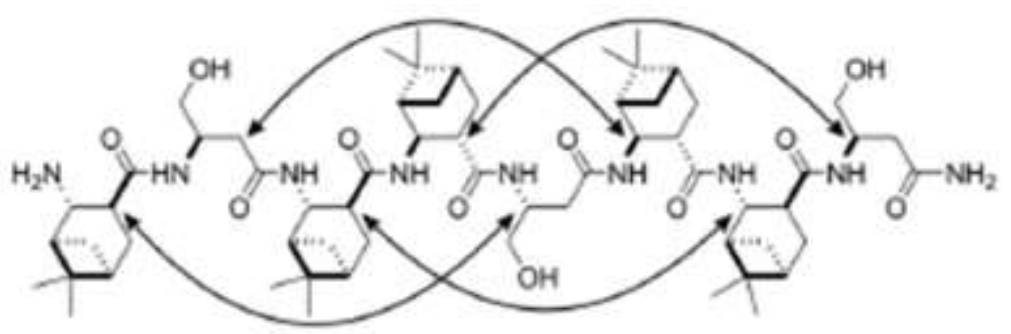

8

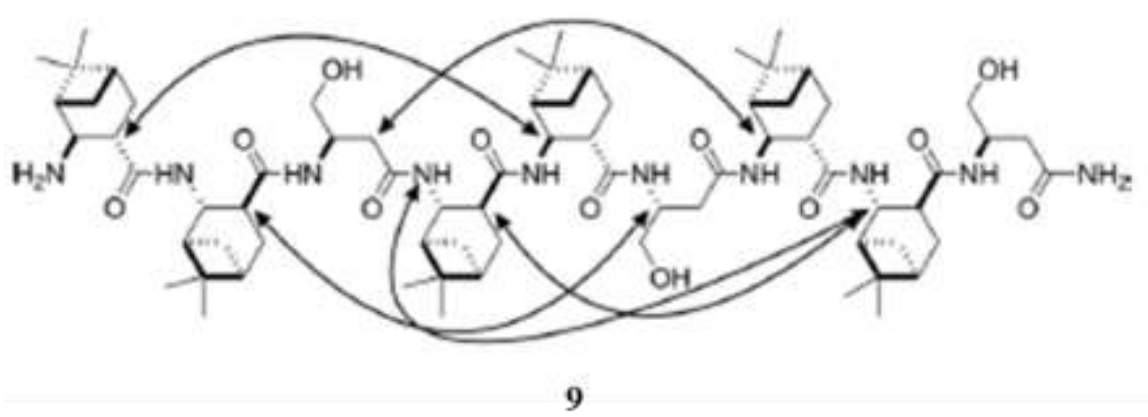

Figure 25. Long-range interactions observed for 8 and 9 in $\mathrm{CD}_{3} \mathrm{OH}$

The structure refinement led to the conclusion that this pattern can be explained by the formation of left-handed $(M) \mathrm{H} 18$ helix geometry, where the ABHC-ABHC repulsions are relieved. The comparison with the ECD results indicated that elongation of the chain with additional ABHC residues leads to preference for the $(i)-(i+4) \mathrm{H}$-bonded H18 helix in $\mathrm{CD}_{3} \mathrm{OH}$. The structure refinement for 9 revealed additional $\mathrm{NOE} \mathrm{C}^{\beta} \mathrm{H}_{\mathrm{i}}-\mathrm{C}^{\alpha} \mathrm{H}_{6}$ and $\mathrm{C}^{\beta} \mathrm{H}_{3}-\mathrm{C}^{\alpha} \mathrm{H}_{8}$ cross-peaks in $\mathrm{CD}_{3} \mathrm{OH}$ (Figure 26), which are not consistent with a self-contained helix; these interactions are in accord with head-to-tail helix contacts. 


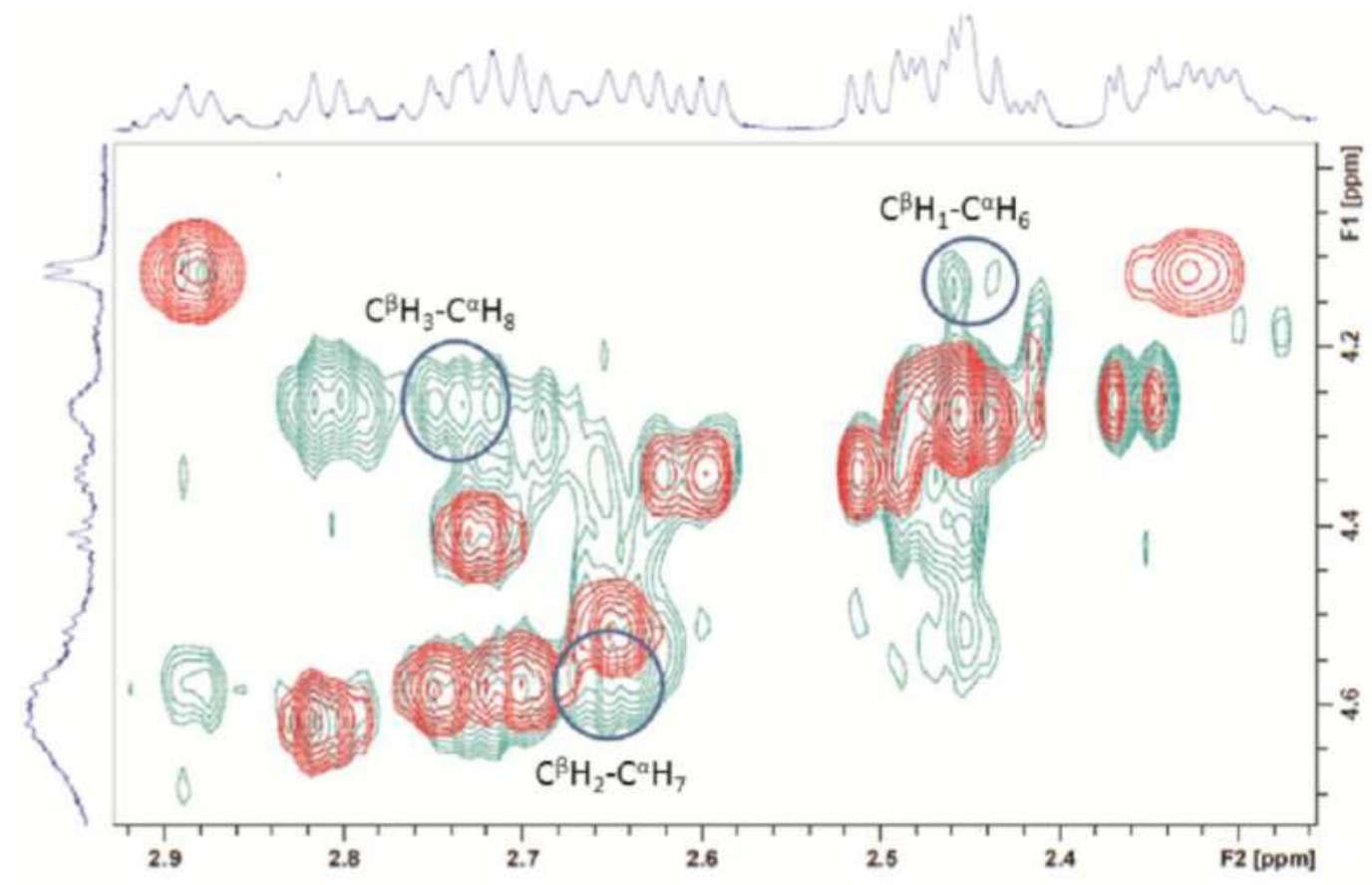

Figure 26. Head-to-tail cross-peaks in the ROESY spectrum of 5 in $\mathrm{CD}_{3} \mathrm{OH}$

To underline the H18 helix formation, theoretical calculations were carried out. The lowestenergy conformers from the simulations of $\mathbf{8}$ and $\mathbf{9}$ were selected and further optimized at the ab initio level. The HF/3-21 basis set in a vacuum was first utilized, as this has been reported to provide a good approximation to the geometry of $\beta$-peptides. ${ }^{200,201}$ The structures converged to the corresponding local minimum of the potential energy surface. To take into account the effects of more diffuse basis sets and the electron correlation, the optimizations were performed at the B3/LYP/6-311G** level. The structure optimizations converged properly and the new foldameric left-handed $(M)$ helices stabilized by 18-membered $\mathrm{H}$-bonded rings were obtained (Figure 27). 

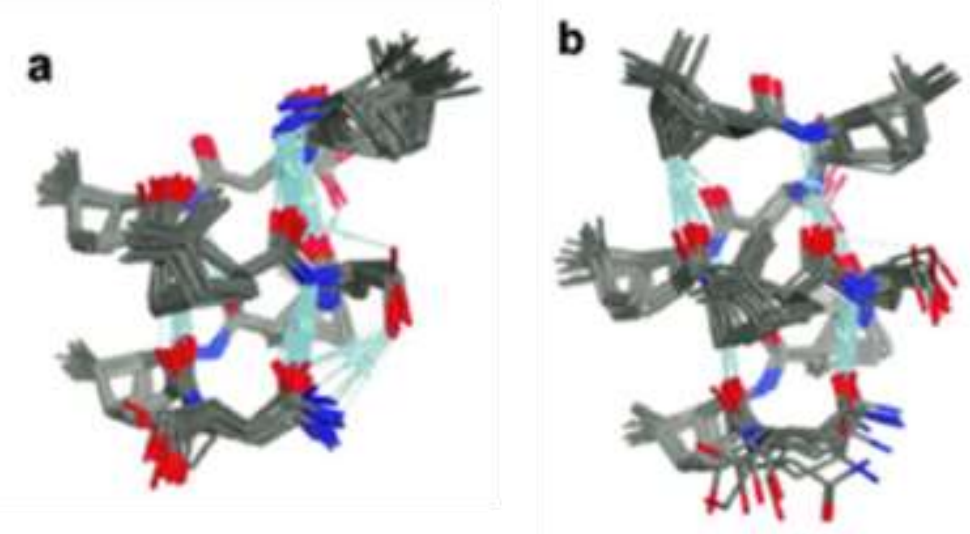

Figure 27. The H18 helix obtained from the NMR structure refinement for 8 (a) and 9 (b)

The sequences contain a number of strongly hydrophobic side-chains potentially facilitating solvophobic self-assembly in the protic $\mathrm{CD}_{3} \mathrm{OH}$, and head-to-tail helix interactions were also observed for 9. To test this phenomenon, concentration-dependent ECD, DOSYNMR and transmission electron microscopy (TEM) measurements were performed on peptides 7-9. The DOSY-NMR results provided direct evidence for the self-assembly processes. The apparent aggregation number converged to a value of 9 for $\mathbf{9}$, reaching a plateau at $100 \mu \mathrm{M}$. For $\mathbf{7}$ and $\mathbf{8}$, the aggregation numbers increased with lower slopes and their behaviour was similar (Figure 28).

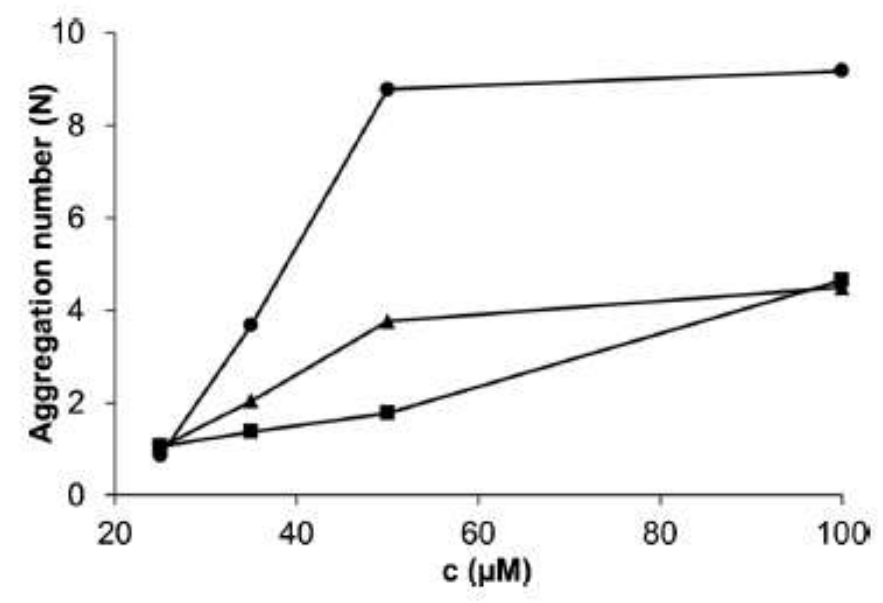

Figure 28. Concentration-dependent aggregation numbers, determined by DOSY-NMR

Deeper ECD analysis revealed concentration-dependent ECD curves (Figure 29). There was an intensity change for 7, but the overall ECD fingerprint corresponding to the H12 helix remained the same in the studied concentration range. This suggests that the self- 
assembly has a certain effect on the $\mathrm{H} 12$ helix for $\mathbf{7}$, but is unable to change the overall secondary structure. For $\mathbf{8}$ and $\mathbf{9}$, the Cotton effects clearly changed sign upon dilution; the positive lobes appeared at around $220 \mathrm{~nm}$ and the negative lobe exhibited a small shift, together with a marked intensity change. At lower concentrations, the curves converged to the features observed for the H12 helix already assigned with the help of 7. It is important that dilution led to higher-intensity ECD curves, indicating that loss of the interchain interactions results in refolding of the foldamers, but not a disordered state. The self-association correlated well with the $\mathrm{H} 12 \rightarrow \mathrm{H} 18$ helix transition and the results strongly suggest that the interchain solvophobic contacts are responsible for the secondary structure change.

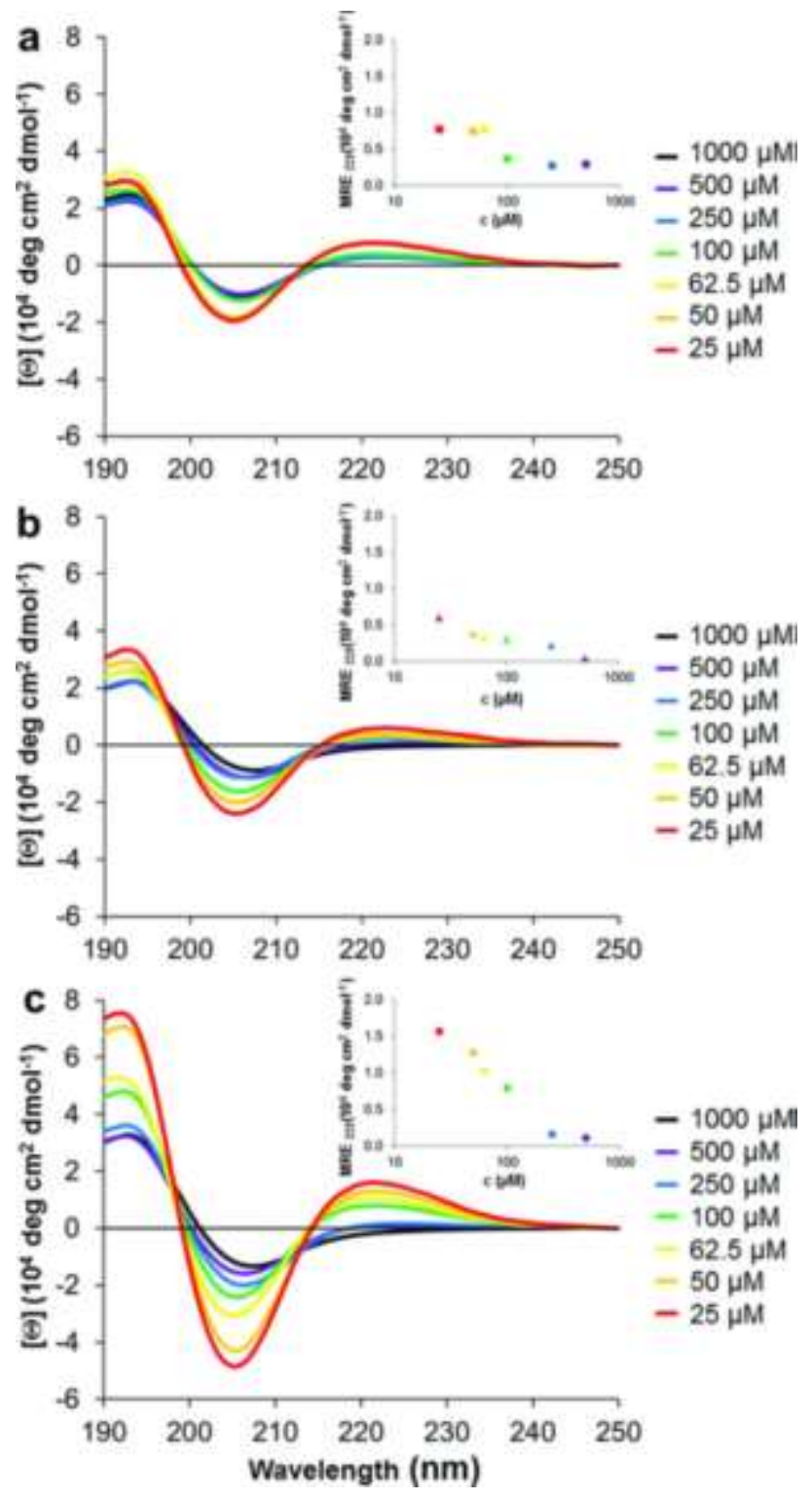

Figure 29. Concentration-dependent ECD data for 7, 8 and 9 in $\mathrm{MeOH}$ 


\subsection{Foldameric $\beta$-H18/20p mixed helix stabilized by head-to-tail contacts: a way to higher-order structures}

Peptidic foldamers are able to form higher-order (tertiary and quaternary) structures; cooperative folding into helix bundles has been shown. ${ }^{31}$ Various $\beta$ - and $\alpha, \beta$-peptide sequences have recently been found to form quaternary structures through self-assembling helical building blocks. ${ }^{32-35}$ Infinite pleated sheet aggregates have also been observed, which appeared in the form of nanostrucuted fibrils. ${ }^{113,129,210,213,214}$ Peptidic foldamers have the ability to fold into large-diameter helices, ${ }^{68,215}$ which can participate in stable axial (head-to-tail) interactions through backbone hydrogen-bonds and side-chain interactions. This phenomenon was observed in gramicidin $\mathrm{A}$, in which axial self-recognition takes place in the membrane environment. ${ }^{216}$ Early results underlined that in peptidic foldamers axial helix-helix interactions are also present in the process of self-association of the $\beta$-peptidic $\mathrm{H} 12$ helix to the large-diameter H18 helix. We were interested to test this phenomenon further, among the mixed foldameric helices.

The mixed H10/H12 helix, ${ }^{217}$ built up from cis-2-aminocyclopentanecarboxylic acid (cisACPC) monomers ${ }^{113}$ is regarded as a pseudosymmetric system. The stereochemically alternating backbone can geometrically form both right- and left-handed helices. The sequence $10[(1 S, 2 R) \text {-ACPC- }(1 R, 2 S)-\mathrm{ACPC}]_{3}-\mathrm{NH}_{2}$ folds into stable right-handed $(P) \mathrm{H} 10 / 12$. Inversion of the backbone configurations of the sequence results in the mirror image 11, which should form a left-handed $(M)$ helix. According to the stereochemical patterning approach, ${ }^{68,215}$ this is equivalent to shifting of the backbone configuration pattern through a monomer unit. Our hypothesis was that manipulation of either the $\mathrm{N}$ - or the $\mathrm{C}$-terminus would promote the deterministic transfer of chiral information along the chain by changing only the helix sense and retaining the H10/12 helical structure. It has been proved that the $\mathrm{N}$-terminus of a peptidic chain has an effect on its propensity towards helix formation ${ }^{218,219}$ and the sense of helicity. ${ }^{220,221}$ To test the presumed effects of changing the N-terminus on the helical sense of the H10/12 helix, new sequences were synthesized by using the Fmoc synthetic protocol (Scheme 4). Compounds of the N-capped derivative of $\mathbf{1 1}$ with an acetyl group 12, a stereochemically matching cis-ACPC 13 and the N-capped derivative of $\mathbf{1 3}$ with an acetyl group 14 were constructed. 

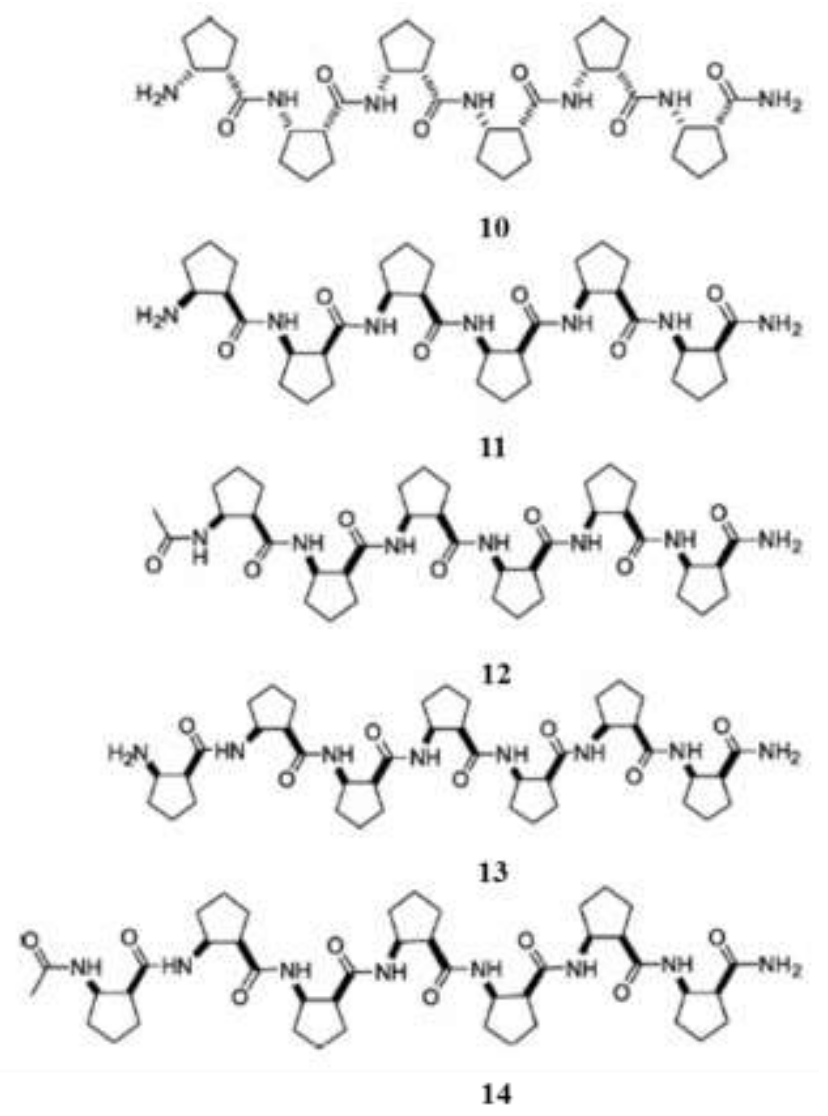

Scheme 4. Structures studied for their helicity

First, ECD measurements were carried out to test the effects of N-capping. It is clear from the data that the frame-shift in the configuration pattern results in mirror-image ECD spectra, which indicates the expected opposite sense of the H10/12M helix (Figure 30).

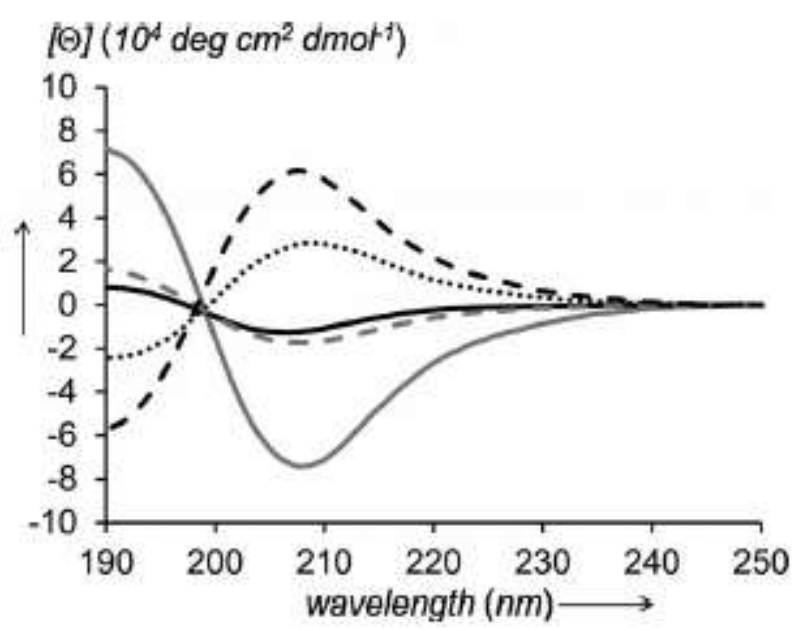

Figure 30. ECD spectra recorded in $\mathrm{MeOH}$ for a $1 \mathrm{mM}$ solution of $\mathbf{1 0}$ (dashed black, taken from ref. ${ }^{113}$ ), 11 (solid grey), 12 (solid black), 13 (dotted black) and 14 (dashed grey) 
Acetylation of the N-terminus furnished a similar, but lower-intensity Cotton effect for 12, which may indicate that the H10/12 helical conformation is still present and the disordered content has increased, or both the right- and left-handed conformations are present together. The additional stereochemically matching cis-ACPC residue at the $\mathrm{N}$-terminus led to a positive Cotton effect, which confirmed that $\mathbf{1 3}$ is a right-handed helix. Acetylation of $\mathbf{1 3}$ led to the predominance of a left-handed helix 14, but the ECD curve showed a lower intensity. These findings support the hypothesis that the $\mathrm{N}$-terminus has a crucial role in the formation of the H10/12 helix and controls the helix sense.

NMR investigation revealed good signal resolution for all the compounds. Direct measurement of the $\mathrm{NH} / \mathrm{ND}$ exchange rates in $\mathrm{CD}_{3} \mathrm{OD}$ indicated the presence of predominantly folded structures (Figure 31).
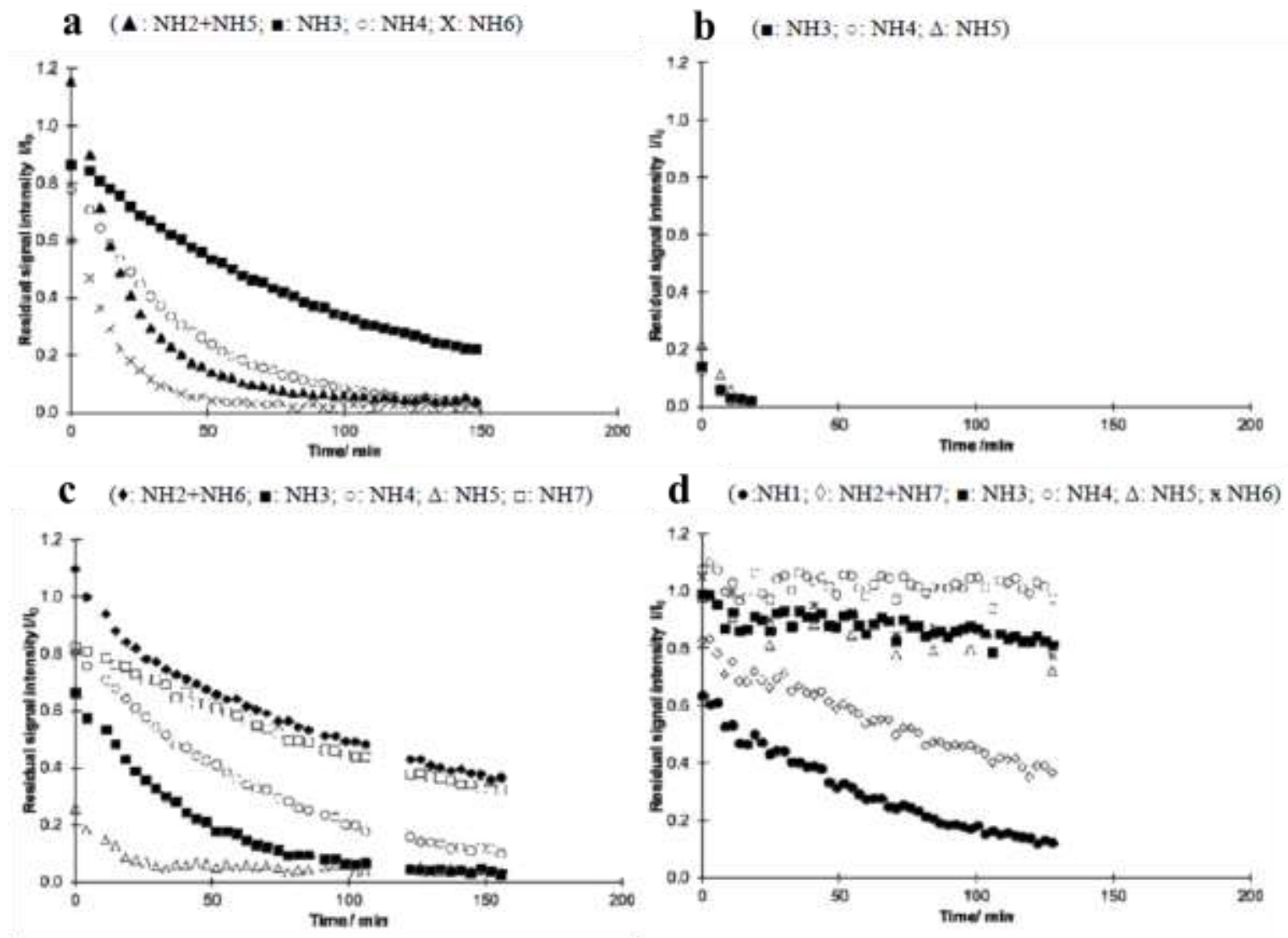

Figure 31. Time dependence of the NH/ND exchange for 11 (a), 12 (b), 13 (c), 14 (d)

ROESY experiments were performed to acquire high-resolution structural data. Characteristic $\mathrm{C}^{\beta} \mathrm{H}_{\mathrm{i}}-\mathrm{NH}_{\mathrm{i}+2}$ and $\mathrm{NH}_{\mathrm{i}}-\mathrm{C}^{\beta} \mathrm{H}_{\mathrm{i}+2}$ long-range $\mathrm{NOE}$ interactions were clearly observed for 11, 12 and 
14 both in $\left[\mathrm{D}_{6}\right] \mathrm{DMSO}$ and in $\mathrm{CD}_{3} \mathrm{OH}$, which strongly supported the predominance of the lefthanded $(M)$ H10/12 helix (Figure 32) .

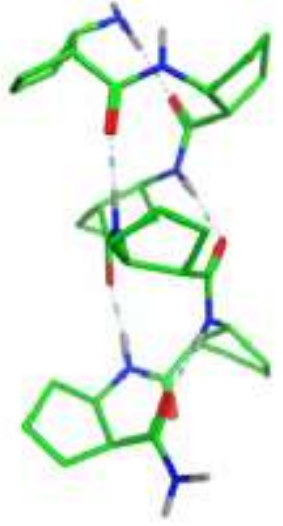

a

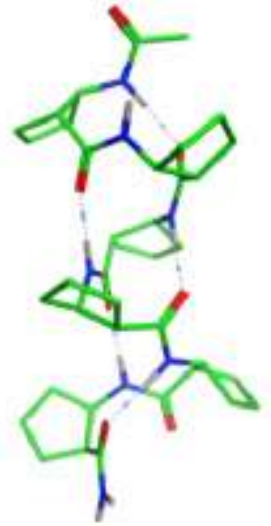

b

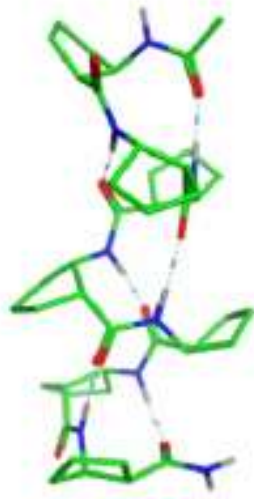

C

Figure 32. Ab initio geometries of 11 (a), 12 (b) and 14 (c)

NOE cross-peaks related to the right-handed $(P)$ conformation or other inconsistent NOE interactions were not detected. This indicates that that the relatively low ECD intensities exhibited by the acetylated derivatives are not a result of disorder or multiple conformation. The vicinal couplings for $\mathrm{NH}_{\mathrm{i}}-\mathrm{C}^{\beta} \mathrm{H}_{\mathrm{i}}$ are also in good agreement with the left-handed $(M) \mathrm{H} 10 / 12$ helical conformation (Table 3).

Table 3. ${ }^{3} J\left(\mathrm{NH}_{\mathrm{i}}-\mathrm{C}^{\beta} \mathrm{H}_{\mathrm{i}}\right)$ values in $\left[\mathrm{D}_{6}\right] \mathrm{DMSO}$ and $\mathrm{CD}_{3} \mathrm{OH}$

\begin{tabular}{lllll}
{$\left[\mathrm{D}_{6}\right] \mathrm{DMSO}$} & \multicolumn{3}{l}{} \\
\hline $\mathrm{i}$ & 2 & 3 & 4 & 5 \\
\hline 1 & - & 9.23 & 7.46 \\
2 & 7.38 & 7.70 & 5.62 & 8.78 \\
3 & 9.35 & 9.27 & 7.71 & 6.87 \\
4 & 7.47 & 8.15 & 8.89 & 9.16 \\
5 & 9.78 & 9.56 & 8.22 & 6.06 \\
6 & 8.05 & 8.09 & 7.80 & 9.23 \\
7 & - & - & & 8.14 \\
\hline $\mathrm{CD}$ & $\mathrm{OH}$ & & 4 & \\
\hline 1 & 2 & 3 & - & 5 \\
\hline 1 & - & 8.80 & 7.52 & 8.04 \\
2 & 7.09 & 7.95 & 9.30 & 7.92 \\
3 & 9.56 & 9.01 & 8.31 & 9.26 \\
4 & 7.09 & 8.32 & 8.79 & 8.02 \\
5 & 9.87 & 9.16 & 7.52 & 9.38 \\
6 & 7.54 & 7.93 & 8.78 & 7.83 \\
7 & - & - & & \\
\hline
\end{tabular}


Analysis of the ROESY spectra revealed solvent-dependent NOE patterns for 13. Previously unreported NOE interactions were observed in $\mathrm{CD}_{3} \mathrm{OH} . \mathrm{C}^{\beta} \mathrm{H}_{\mathrm{i}}-\mathrm{NH}_{\mathrm{i}+4}$ and $\mathrm{NH}_{\mathrm{i}}-\mathrm{C}^{\beta} \mathrm{H}_{\mathrm{i}+4}$ interactions could be clearly observed, and $\mathrm{C}^{\alpha} \mathrm{H}_{1}-\mathrm{C}^{\beta} \mathrm{H}_{6}, \mathrm{C}^{\beta} \mathrm{H}_{3}-\mathrm{NH}_{7}$ and $\mathrm{NH}_{4}-\mathrm{C}^{\beta} \mathrm{H}_{6} \mathrm{NOE}$ contacts could also be found (Figure 33).

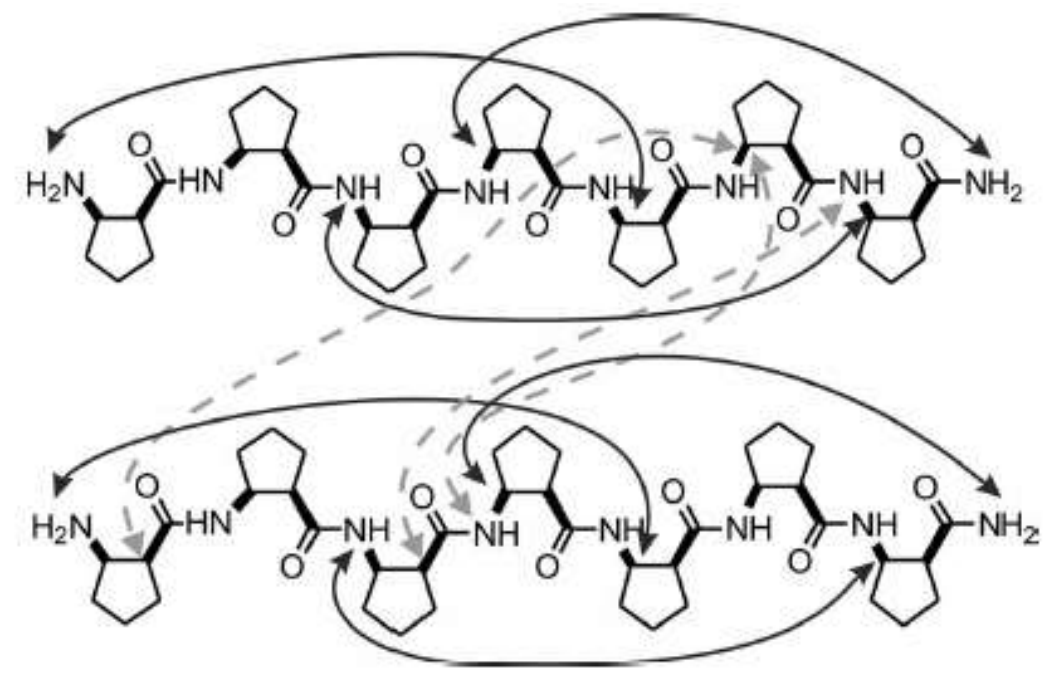

Figure 33. NOE interactions observed for 13 in $\mathrm{CD}_{3} \mathrm{OH}$. Black arrows indicate intramolecular $(i)-(i+4)$ contacts related to the H18/20p helical geometry, and grey dashed arrows indicate head-to-tail helix-helix NOEs arising from self-association.

Since the ${ }^{3} J\left(\mathrm{NH}_{\mathrm{i}}-\mathrm{C}^{\beta} \mathrm{H}_{\mathrm{i}}\right)$ couplings exhibited the pattern expected for a mixed helix and the very low NH/ND exchange rates (see Fig. 31) were detected, we adopted the hypothesis of the interchain origin of the outlier NOEs. The conformational search with the regular $(i)-(i+4)$ interactions and subsequent manual docking of the secondary structure units led to the conclusion that the observed NOE patterns are fully in accord with right-handed $(P) \mathrm{H} 18 / 20$ helices assembled through head-to-tail interactions (Figure 34). 


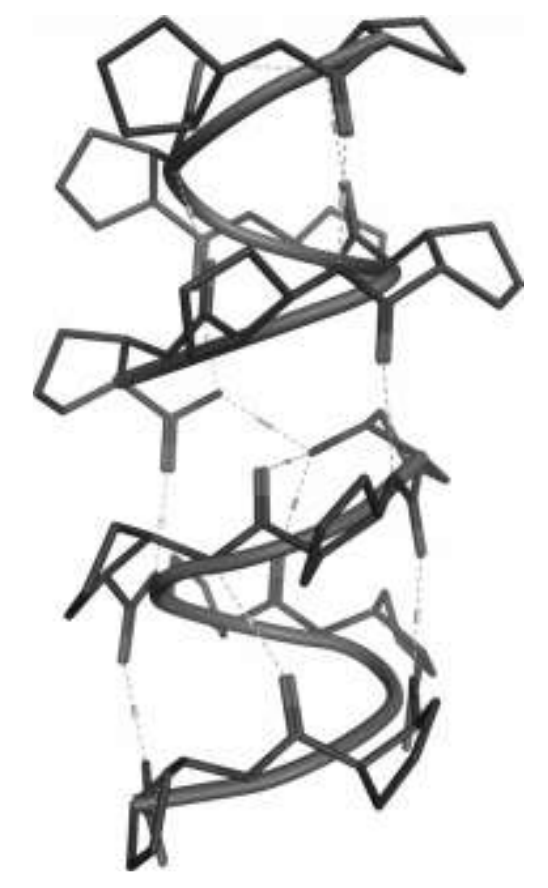

Figure 34. H18/20 $p$ mixed helix head-to-tail dimer of 13 obtained by NMR structure refinement in $\mathrm{CD}_{3} \mathrm{OH}$ and a final ab initio geometry optimization ${ }^{222}$ at the $\mathrm{B} 3 \mathrm{LYP} / 6$ $311 \mathrm{G}^{* *}$ level of theory

This finding is also in good correlation with the positive Cotton effect found with the ECD; however, its intensity cannot be compared directly with those of $\mathbf{1 0}$ and $\mathbf{1 1}$. In contrast with the findings in $\mathrm{CD}_{3} \mathrm{OH}$, in $\left[\mathrm{D}_{6}\right] \mathrm{DMSO}$ only $(i)-(i+2)$ long-range NOEs were identified for 13. Some of the interactions $\left(\mathrm{NH}_{1}-\mathrm{C}^{\beta} \mathrm{H} 3, \mathrm{C}^{\beta} \mathrm{H}_{2}-\mathrm{NH}_{\mathrm{i}+4}\right.$ and $\left.\mathrm{C}^{\beta} \mathrm{H}_{4}-\mathrm{NH}_{\mathrm{i}+6}\right)$ indicated the presence of a right-handed $\mathrm{H} 10 / 12$ helix, but a $\mathrm{C}^{\beta} \mathrm{H}_{5}-\mathrm{NH}_{\mathrm{i}+7}$ interaction at the $\mathrm{C}$ - terminus is a sign of an $M$ type fold. The most likely explanation for this is in the presence of both helix senses and partially folded states along the chain, because $\mathrm{N}$-terminal helix nucleation is less effective in [D6]DMSO. NMR findings support the view that the formation of the large-diameter H18/20 helix is coupled to the head-to-tail association in $\mathrm{CD}_{3} \mathrm{OH}$ and the helix-helix interactions are stabilized by four interchain hydrogen-bonds, $\mathrm{NH}_{8}-\mathrm{NH}_{1}, \mathrm{NH}_{2}-\mathrm{CO}_{5}, \mathrm{NH}_{7}-\mathrm{CO}_{2}$ and $\mathrm{NH}_{4}-\mathrm{CO}_{7}$, which interactions are disrupted in the chaotropic [D6]DMSO. The solvent-dependent helix self-association process of $\mathbf{1 3}$ was further investigated by concentration-dependent DOSY NMR measurements. The aggregation number at a concentration of $100 \mu \mathrm{M}$ was 3 , which rose to 8 at $1 \mathrm{mM}$ (Figure 35). The other three peptides (11, 12 and 14) did not exhibit selfassociation in the solution phase. 


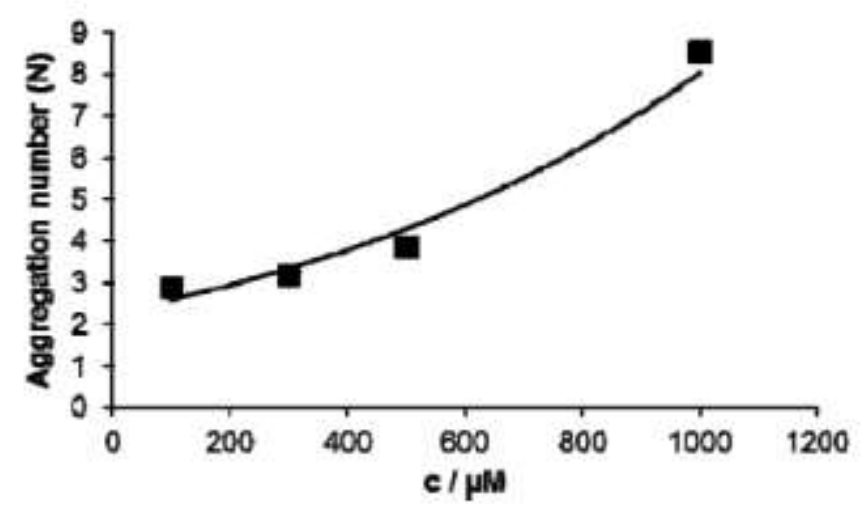

Figure 35. Concentration-dependent aggregation number of $\mathbf{1 3}$

To study the effect of self-association on the secondary structure, concentration-dependent ECD spectra were recorded (Figure 36).

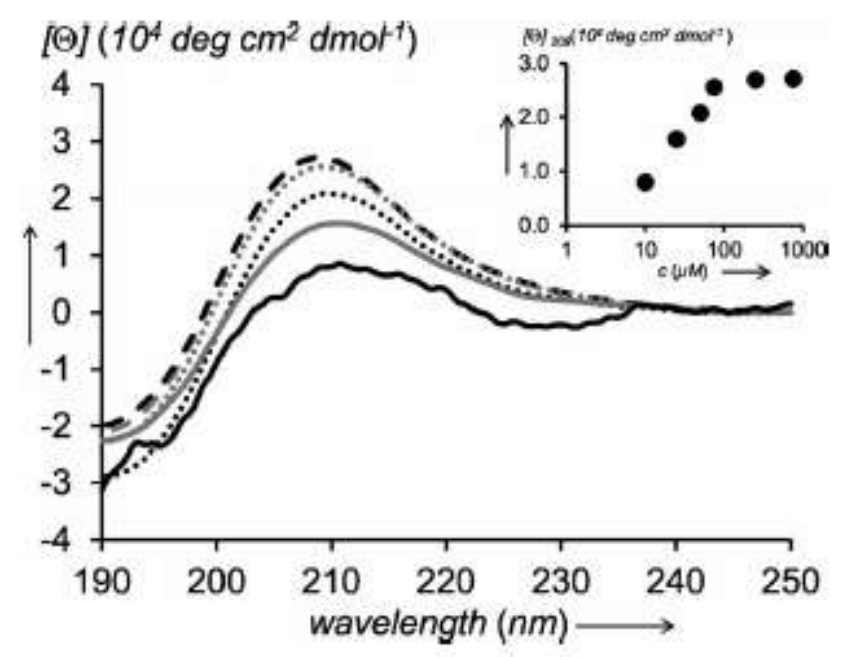

Figure 36. Concentration-dependent ECD spectra of $\mathbf{1 3}$ in $\mathrm{MeOH}$

No significant change was observed upon dilution in the range $1 \mathrm{mM}$ to $100 \mu \mathrm{M}$. Although the DOSY data indicated a decreasing aggregation number, the interchain interaction was still predominant, as reflected in the ECD spectra. Below $100 \mu \mathrm{M}$, the concentration had a significant effect on the ECD response, the intensity of the positive band decreased and a red shift of the Cotton effect was detected. Unfortunately, a high-resolution structure could not be determined at $10 \mu \mathrm{M}$. We assumed that the ECD spectrum observed can be explained by the partial refolding of the structure into the H10/12 helix and the formation of possible both $P$ and $M$ helices, similarly as observed in $\left[\mathrm{D}_{6}\right] \mathrm{DMSO}$. These observations strongly support the view 
that head-to-tail association makes a crucial contribution to the stability of the large-diameter right-handed H18/20 helix and that axial helix-helix interaction occurs in a cooperative way.

\subsection{Intermolecular helix-helix association}

As mentioned earlier, horizontally and vertically amphiphilic H14 helices containing hydrophobic residues are prone to solvophobically driven self-association to form helical bundles, which means that the major driving force for the process in polar solvents is the solvophobic attractive interaction between the non-polar side-chains. The propensity for selfassociation increases even better with the growth of the chain length.

In our case, the hexameric H12 helix, which was also constructed from hydrophobic ABHC residues, is capable of self-association in MeOH. ROESY NMR measurements suggested an intermolecular side-by-side helix bundle-type association for all these peptides, as no head-totail related NOEs were found during characterization of the spectra. Another important observation is that these peptides retained their individual secondary structure in the associated state.

Those oligomers where the ABHC residues are replaced by $\beta^{3}$-hSer residues are already able to exhibit a conformational transition to a large-diameter H18 helix in the heptamernonamer range controlled by a self-association process. The hydrophobic side-chains in the sequences strongly facilitating solvophobic self-assembly in polar solvent and head-to-tail helix interactions were also revealed in the nonamer sequence. The formation of the H18 helix was reversible and found to be solvent- and concentration-dependent. Upon dilution, the $\mathrm{H} 18 \rightarrow$ H12 helix transition could be observed.

Helical self-association was also observed for the mixed H10/12 helix constructed from ACPC residues. Although our designed heptameric peptide sequence contained only hydrophobic side-chains, the NMR results revealed axial helix-helix (head-to-tail) interactions in a polar solvent which led to a serendipitous new mixed H18/20 helix, the largest-diameter $\beta$ peptidic mixed helix to date.

We can conclude that these coupled folding and self-assebly processes with axial helixhelix interactions offer an alternative mode to the formation of higher-order structures for peptide foldamers. 


\section{Summary}

Various helically ordered $\beta$-peptides (1-14) were designed to map different structuring effects on the preferred secondary structure and reveal the possibility of higher-order motifs. Peptides were synthesized on a solid support through Fmoc chemistry. The synthesized sequences were purified by RP-HPLC. The purified peptides were characterized by analytical HPLC and MS. The structures of the peptides were studied with molecular modelling, various NMR techniques and ECD.

The long-range side-chain steric repulsion concept proved to be a novel route for the shaping of the desired helical secondary structure.

The apopinane-derived, bulky trans-ABHC monomers with their special side-chain shape caused steric clashes between positions $(i)-(i+3)$ in the peptide sequence, which disfavours the H14 helical fold and induces the formation of the H12 helix.

The chain-length-dependent investigations revealed that oligomers containing up to five trans-ABHC residues (3 and 4) unambiguously stabilize the $\mathrm{H} 12$ helix.

The $\beta$-peptidic $\mathrm{H} 12$ helix structure tolerates open-chain $\beta^{3}$-amino acid residues incorporated in the sequence.

Oligomers with different patterns of trans-ABHC and $\beta^{3}$-hSer residues (5-9) were investigated in the heptamer-nonamer range. At least two repulsive contacts of the transABHC pairs are necessary in positions $(i)-(i+3)$ to prevent the formation of the H14 helix in the heptameric sequences (5-7).

We further proved that the $\mathrm{H} 12$ helix constructed from the trans-ABHC residues is capable of chain-length-dependent self-association.

Solvent-dependent conformational polymorphism was observed for the octamer $\mathbf{8}$ and nonamer 9, supported by NMR-ROESY measurements. In [ $\left.\mathrm{D}_{6}\right] \mathrm{DMSO}$, the H12 helix remained a stable conformation, whereas a large-diameter H18 helix was clearly detected in polar medium. Head-to-tail long-range NOE interactions were also detected for compound $\mathbf{9}$, which indicated higher-order structural forms in the solution phase.

Concentration-dependent ECD and DOSY-NMR measurements confirmed the selfassociation process in $\mathrm{MeOH}$ for compounds (8 and $\mathbf{9})$, which correlated well with a $\mathrm{H} 12 \rightarrow$ H18 helix transition. The self-assembly was also observed for heptameric 7, but was unable to change its overall $\mathrm{H} 12$ helical structure. These results supported that foldameric helix refolding promotes higher-order packing of the helices in $\mathrm{MeOH}$. 
We extended the chain-lengthening approach to alternating heterochiral $\beta$-peptidic sequences (11-14).

We proved that manipulation of the $\mathrm{N}$-terminus of $\mathbf{1 0}$ is able to determine the transfer of chiral information along the helix by changing the helicity of the chain.

We showed that the alternating heterochiral cis-ACPC-containing heptameric chain $\mathbf{1 3}$ exhibits a dramatic change in the helix diameter, and the NMR structure refinement revealed a novel, concentration-dependent mixed H18/20 helical conformation, stabilized by intramolecular $(i)-(i+4)$ hydrogen-bonding contacts, whereas hexameric $\mathbf{1 0}$ and $\mathrm{N}$-acetylated sequences (12 and 14) formed the well-known H10/12 helix. The manifestation of the H18/20 was found to be solvent-dependent, and $\mathbf{1 3}$ has opposite handedness relative to the other peptides (11, 12 and 14).

The folding and self-association processes with axial helix-helix interactions provide an alternative route for higher-order structure formation for the large-diameter foldameric helices. The NMR and ECD results strongly suggested that mixed H18/20 helix is stabilized by intermolecular head-to-tail contacts. 


\section{Acknowledgements}

This work was carried out in the Institute of Pharmaceutical Chemistry at the University of Szeged in the period 2008-2012.

I would like to express my kindest thanks to Prof. Dr. Fülöp Ferenc, Head of the Institute of Pharmaceutical Chemistry, for providing me with the opportunity to carry out scientific work in the Institute of Pharmaceutical Chemistry, and for his continuous support.

My warmest thanks are also due to my supervisor, Prof. Dr. Tamás Martinek, Head of the Institute of Pharmaceutical analysis, for his guidance of my work, his always inspiring ideas, his useful advice and his constructive criticism.

I owe special thanks to Dr. István Mándity, lecturer for his valuable help at the beginning of my scientific work.

I am really grateful to all the staff members of the NMR group for their valuable help and support, and especially to István Simon, who has helped me so generously in the NMR laboratory. Many thanks to all my colleagues in the Institute of Pharmaceutical Chemistry and in the Institute of Pharmaceutical Analysis for the favourable atmosphere.

I wish to express my thanks to Dr. Milán Szabó (former staff member at the Biological Research Centre, Hungarian Academy of Sciences, Szeged) who provided technical help and practical advice in the ECD measurements.

Finally, I am deeply grateful to my Mother for her loving care, patience and support throughout my entire life, and to my Husband, who has helped and encouraged me during these years. 


\section{References}

1. Barlow, D. J.; Thornton, J. M. J. Mol. Biol. 1988, 201, 601.

2. Cheng, R. P.; DeGrado, W. F. J. Am. Chem. Soc. 2001, 123, 5162.

3. Hecht, S.; Huc, I. Foldamers : structure, properties, and applications; Wiley-VCH: Weinheim, 2007

4. Venkatraman, J.; Shankaramma, S. C.; Balaram, P. Chem. Rev. 2001, 101, 3131.

5. Cubberley, M. S.; Iverson, B. L. Curr. Opin. in Chem. Biol. 2001, 5, 650.

6. Stigers, K. D.; Soth, M. J.; Nowick, J. S. Curr. Opin. in Chem. Biol. 1999, 3, 714.

7. Hill, D. J.; Mio, M. J.; Prince, R. B.; Hughes, T. S.; Moore, J. S. Chem. Rev. 2001, 101, 3893.

8. Seebach, D.; Ciceri, P. E.; Overhand, M.; Jaun, B.; Rigo, D.; Oberer, L.; Hommel, U.; Amstutz, R.; Widmer, H. Helv. Chim. Acta 1996, 79, 2043.

9. Gellman, S. H. Acc. Chem. Res. 1998, 31, 173.

10. Appella, D. H.; Christianson, L. A.; Klein, D. A.; Powell, D. R.; Huang, X. L.; Barchi, J. J.; Gellman, S. H. Nature 1997, 387, 381.

11. Appella, D. H.; Christianson, L. A.; Karle, I. L.; Powell, D. R.; Gellman, S. H. J. Am. Chem. Soc. 1996, 118, 13071.

12. Cheng, R. P.; DeGrado, W. F. J. Am. Chem. Soc. 2001, 123, 5162.

13. Cheng, R. P.; Gellman, s. H.; DeGrado, W. F. Chem. Rev. 2001, 101, 3219.

14. Cheng, R. P. Curr. Opin. in Struct. Biol. 2004, 14, 512.

15. Seebach, D.; Beck, A. K.; Bierbaum, D. J. Chem .Biodiv. 2004, 1, 1111.

16. Liu, D.; DeGrado, W. F. J. Am. Chem. Soc. 2001, 123, 7553.

17. Goodman, C. M.; Choi, S.; Shandler, S.; DeGrado, W. F. Nat. Chem. Biol. 2007, 3, 252.

18. Fulop, F.; Martinek, T. A.; Toth, G. K. Chem. Soc, Rev. 2006, 35, 323.

19. Martinek, T. A.; Fulop, F. Chem. Soc. Rev. 2012, 41, 687.

20. Martinek, T. A.; Fulop, F. Eur. J. Biochem. 2003, 270, 3657.

21. Fulop L.; Mandity, I. M.; Juhasz, G.; Szegedi, V.; Hetenyi, A.; Weber, E.; Bozso, Z.; Simon, D., Benko, M.; Kiraly, Z.; Martinek, T. A. PLoS ONE 2012, 7, e39485.

22. Wieprecht, T.; Apostolov, O.; Beyermann, M.; Seelig, J. J. Mol. Biol. 1999, 294, 785.

23. Wieprecht, T.; Beyermann, M.; Seelig, J. Biophys. Chem. 2002, 96, 191.

24. Sakajiri, K.; Satoh, K.; Kawauchi, S.; Watanabe, J. J. Mol. Struct. 1999, 476, 1.

25. Otoda, K.; Kitagawa, Y.; Kimura, S.; Imanishi, Y. Biopolymers 1993, 33, 1337. 
26. Vieira-Pires, R. S.; Morais-Cabral, J. H. J. Gen. Physiol. 2010, 136, 585.

27. Yoder, G.; Polese, A.; Silva, R. A. G. D; Formaggio, F.; Crisma, M.; Broxterman, Q. B.; Kamphius, J.; Toniolo, C.; Keiderling, T. A. J. Am. Chem. Soc. 1997, 119, 10278.

28. Bellanda, M.; Mammi, S.; Geremia, S.; Demitri, N.; Randaccio, L.; Broxtermann, Q. B.; Kaptein, B.; Pengo, P.; Pasquato, L.; Scrimin, P. Chem. Eur. J. 2007, 13, 407.

29. Hayen, A.; Schmitt, M. A.; Ngassa, F. N.; Thomasson, K. A.; Gellman S. H. Angew. Chem. Int. Ed. 2004, 43, 505.

30. Hetenyi, A.; Mandity, I. M.; Martinek, T. A.; Toth, G. K.; Fulop, F. J. Am. Chem. Soc. 2005, $127,547$.

31. Cheng, R. P.; DeGrado, W. F. J. Am. Chem. Soc. 2002, 124, 11564.

32. Goodman, J. L.; Petersson, E. J.; Daniels, D. S.; Qiu, J. X.; Schepartz, A. J. Am. Chem. Soc. 2007, 129, 14746.

33. Horne, W. S.; Price, J. L.; Keck, J. L.; Gellman, S. H. J. Am. Chem. Soc. 2007, 129, 14746.

34. Giulianio, M. W.; Horne, W. S.; Gellman, S. H. J. Am. Chem. Soc. 2009, 131, 9860.

35. Price, J. L.; Horne, W. S.; Gellman, S. H. J. Am. Chem. Soc. 2007, 129, 6376.

36. Seebach, D.; Matthews, J. L. Chem. Comm. 1997, 2015.

37. Armand, P.; Kirschenbaum, K.; Goldsmith, R. A.; Farr-Johnes, S; Barron, A. E.; Truong, K. T. V.; Dill, K. A.; Mierke, D. F.; Cohen, F. E.; Zuckermann, R. N.; Bradley, E. K. Proc. Natl. Acad. Sci. U.S.A. 1998, 95, 4309.

38. Burkoth, T. S.; Beausoleil, E.; Kaur, S.; Tang, D. Z.; Cohen, F. E.; Zuckermann, R. N. Chem. Biol. 2002, 9, 647.

39. Lee, B-C.; Zuckermann, R. N.; Dill, K. A. J. Am. Chem. Soc. 2005, 127, 10999.

40. Hintermann, T.; Gademann, K.; Jaun, B.; Seebach, D. Helv. Chim. Acta 1998, 81, 983.

41. Hanessian, S.; Luo, X.; Schaum, R.; Michnick, S. J. Am. Chem. Soc. 1998, 120, 8569.

42. Sharma, G. V. M.; Jayaprakash, P.; Narsimulu, K.; Sankar, A. R.; Reddy, K. R.; Krishna, P. R.; Kunwar, A. C. Angew. Chem. Int. Ed. 2006, 45, 2944.

43. Seebach, D.; Hook, D. F.; Glattli, A. Biopolymers 2006, 84, 23.

44. Salaun, A.; Potel, M.; Roismel, T.; Gall, P.; Le Grel, P. J. Org. Chem. 2005, 70, 6499.

45. Le Grel, P.; Salaun, A.; Potel, M.; Le Grel, B.; Lassagne, F. J. Org. Chem. 2006, 71, 5638 .

46. Zega, A. Curr. Med. Chem. 2005, 12, 589.

47. Melendez, R. E.; Lubell, W. D. J. Am. Chem. Soc. 2004, 126, 6759. 
48. Violette, A.; Averlant-Petit, M. C.; Semetey, V.; Hemmerlin, C.; Casimir, R.; Graff, R.; Marraud, M.; Briand, J. P.; Rognan, D.; Guichard, G. J. Am. Chem. Soc. 2005, 127, 2156.

49. Violette, A.; Lancelot, N.; Poschalko, A.; Piotto, M.; Briand, J. P.; Raya, J.; Elbayed, K.; Bianco, A.; Guichard, G. Chem. Eur. J. 2008, 14, 3874.

50. Fischer, L.; Claudon, P.; Pendem, N.; Miclet, E.; Didierjean, C.; Ennifar, E.; Guichard, G. Angew. Chem. Int. Ed. 2010, 49, 1067.

51. Li. X.; Yang, D. Chem. Comm. 2006, 3367.

52. Yang, D.; Liu, G. J.; Hao, Y.; Li, W.; Dong, Z. M.; Zhang, D. W.; Zhu, N. Y. Chem. Asian J. 2010, 5, 1356.

53. Smith, A. B.; Keenan, T. P.; Holcomb, R. C.; Sprengeler, P. A.; Guzman, M. C.; Wood, J. L.; Carroll, P. J.; Hirschmann, R. J. Am. Chem. Soc. 1992, 114, 10672.

54. Smith, A. B.; Wang, W. Y.; Charnley, A. K.; Carroll, P. J.; Kenesky, C. S.; Hirschmann, R. Org. Lett. 2010, 12, 2990.

55. De Pol, S.; Zorn, C.; Klein, C. D.; Zerbe, O.; Reiser, O. Angew. Chem. Int. Ed. 2004, 43,511 .

56. Torres, E.; Gorrea, E.; Burusco, K. K.; Da Silva, E.; Nolis, P.; Rua, F.; Boussert, S.; Diez-Perez, I.; Dannenberg, S.; Izquierdo, S.; Giralt, E.; Jaime, C.; Branchadell, V.; Ortuno, R. M. Org. Biomol. Chem. 2010, 8, 564.

57. Schmitt, M. A.; Weisblum, B.; Gellman, S. H. J. Am. Chem. Soc. 2004, 126, 6848.

58. Choi, S. H.; Guzei, I. A.; Spencer, L. C.; Gellman, S. H. J. Am. Chem. Soc. 2008, 130, 6544.

59. Horne, W. S.; Gellman, S. H. Acc. Chem. Res. 2008, 41, 1399.

60. Baldauf, C.; Gunther, R.; Hofmann, H-J. J. Org. Chem. 2006, 71, 1200.

61. Vasudev, P. G.; Chatterjee, S.; Ananda, K.; Shamala, N.; Balaram, P. Angew. Chem. Int. Ed. 2008, 47, 6430.

62. Chatterjee, S.; Vasudev, P. G.; Ananda, K.; Raghothama, S.; Shamala, N.; Balaram, P. J. Org. Chem. 2008, 73, 6595.

63. Sharma, G. V. M.; Jadhav, V. B.; Ramakrishna, K. V. S.; Jayaprakash, P.; Narsimulu, K.; Subash, V.; Kunwar, A. C. J. Am. Chem. Soc. 2006, 128, 14657.

64. Guo, L.; Almeida, A. M.; Zhang, W.; Reidenbach, A. G.; Choi, S. H.; Guzei, I. A.; Gellman, S. H. J. Am. Chem. Soc. 2010, 132, 7868. 
65. Tolstikova, T. G.; Morozova, E. A.; Pavlova, A. V.; Bolkunov, A. V.; Dolgikh, M. P.; Koneva, E. A.; Volcho, K. P.; Salakhutdinov, N. F.; Tolstikov, G. A. Dokl. Chem. 2008, $422,248$.

66. Abele, S.; Seebach, D. Eur. J.Org. Chem. 2000, 1.

67. Forro, E.; Fulop, F. Chem. Eur. J. 2007, 13, 6397.

68. Mandity, I. M.; Weber, E.; Martinek, T. A.; Olajos, G.; Toth, G. K.; Vass, E.; Fulop, F. Angew. Chem. Int. Ed. 2009, 48, 2171.

69. Fulop, F. Il Farmaco 2000, 55, 181.

70. Fulop, F. Chem. Rev. 2001, 101, 2181.

71. Seebach, D.; Overhand, M.; Kuhnle, F. N. M.; Martinoni, B.; Oberer, L.; Hommel, U.; Widmer, H. Helv. Chim. Acta 1996, 79, 913.

72. Barenjee, A.; Balaram, P. Curr. Science 1997, 73, 1067

73. Wu, Y-D.; Wang, D-P. J. Am. Chem. Soc. 1998, 120, 13485.

74. Wu, Y-D.; Wang, D-P. J. Am. Chem. Soc. 1999, 121, 9352.

75. Appella, D. H.; Christianson, L.A.; Karle, I. L.; Powell, D. R.; Gellman, S. H. J. Am. Chem. Soc. 1999, 121, 6206.

76. Appella, D. H.; Barchi, J. J.; Durell, S. R.; Gellman, S. H. J. Am. Chem. Soc. 1999, 121, 2309.

77. Barchi, J. J.; Huang, X.; Appella, D. H.; Christianson, L. A.; Durell, S. R.; Gellman, S. H. J. Am. Chem. Soc. 2000, 122, 2711.

78. Schinnerl, M.; Murray, J. K.; Langenhan, J. M.; Gellman, S. H. Eur. J. Org. Chem. 2003, 721 .

79. Izquierdo, S.; Kogan, M. J.; Parella, T.; Moglioni, A. G.; Branchadell, V.; Giralt, E.; Ortuno, R. M. J. Org. Chem. 2004, 69, 5093.

80. Seebach, D.; Overhand, M.; Kühnle, F. N. M.; Martinoni, B. Helv. Chim. Acta 1996, 79, 913.

81. Hintermann, T.; Seebach, D. Synlett 1997, 437.

82. Seebach, D.; Schreiber, J. V.; Arvidsson, P. I.; Frackenpohl, J. Helv. Chim. Acta 2001, $84,271$.

83. Raguse, T. L.; Lai, J. R.; Gellman, S. H. Helv. Chim. Acta 2002, 85, 4155.

84. Lee, M.; Raguse, T. L.; Schinnerl, M.; Pomerantz, W. C.; Wang, X.; Wipf, P.; Gellman, S. H. Org. Lett. 2007, 9, 1801.

85. Seebach, D.; Jaboci, A.; Rueping, M.; Gademann, K.; Ernst, M.; Jaun, B. Helv. Chim. Acta 2000, 83, 2115. 
86. Abele, S.; Guichard, G.; Seebach, D. Helv. Chim. Acta 1998, 81, 2141.

87. Arvidsson, P. I.; Rueping, M.; Seebach, D. Chem. Comm. 2001, 649.

88. Kaur, K.; Sprules, T.; Soliman W.; Beleid, R.; Ahmed, S. Biochim. et Biophys. Acta 2008, 1784, 658 .

89. Vaz, E.; Pomerantz, W. C.; Geyer, M.; Gellman, S. H.; Brunsveld, L. ChemBioChem 2008, 9, 2254.

90. Norgren, A. S.; Arvidsson, P. I. J. Org. Chem. 2008, 73, 5272.

91. Applequist, J.; Bode, K. A.; Appella, D. H.; Christianson, L. A.; Gellman, S. H. J. Am. Chem. Soc. 1998, 120, 4891.

92. Appella, D. H.; Christianson, L. A.; Klein, D. A.; Richards, M. R.; Powell, D. R.; Gellman, S. H. J. Am. Chem. Soc. 1999, 121, 7574.

93. Wang, X.; Espinosa, J. F.; Gellman, S. H. J. Am. Chem. Soc. 2000, 122, 4821.

94. Lee, H-S.; Syud, F. A.; Wang, X.; Gellman, S. H. J. Am. Chem. Soc. 2001, 123, 7721.

95. LePlae, P. R.; Umezawa, N.; Lee, H-S.; Gellman, S. H. J. Org. Chem. 2001, 66, 5629.

96. Park, J-S.; Lee, H-S.; Lai, J. R.; Kim, B. M.; Gellman, S. H. J. Am. Chem. Soc. 2003, 125,8539 .

97. Abraham, E.; Bailey, C. W.; Claridge, T. D. W.; Davies, S. G.; Ling, K. B.; Odell, B.; Rees, T. L.; Roberts, P. M.; Russell, A. J.; Smith A. D.; Smith, L. J.; Storr, H. R.; Sweet, M. J.; Thompson, A. L.; Tranter, G. E.; Watkin, D. J. Tetrahedron: Asymmetry 2010, $21,1797$.

98. Abraham, E.; Claridge, T. D. W.; Davies, S. G.; Odell, B.; Roberts, P. M.; Russell, A. J.; Smith A. D.; Smith, L. J.; Storr, H. R.; Sweet, M. J.; Thompson, A. L.; Thomson, J. E.; Tranter, G. E.; Watkin, D. J. Tetrahedron: Asymmetry 2011, 22, 69.

99. Lee, H-S.; LePlae, P. R.; Porter, E. A.; Gellman, S. H. J. Org. Chem. 2001, 66, 3597.

100. Porter, E. A.; Wang, X.; Schmitt, M. A.; Gellman, S. H. Org. Lett. 2002, 4, 3317.

101. Woll, M. G.; Fisk, J. D.; LePlae, P. R.; Gellman, S. H. J. Am. Chem. Soc. 2002, 124, 12447.

102. Hetenyi, A.; Toth, G. K.; Somlai, C.; Vass, E.; Martinek, T. A.; Fulop, F. Chem. Eur. J. 2009, 15, 10736.

103. Fernandes, C.; Faure, S.; Pereira, E.; Théry, V.; Declerck, V.; Guillot, R.; Aitken, D. Org. Lett. 2010, 12, 3606.

104. Axelsen, P.; Winkler, J. D. Angew. Chem. Int. Ed. 2001, 40, 743.

105. Claridge, T. D. W.; Goodman, J. M.; Moreno, A.; Angus, D.; Barker, S. F.; 106. Taillefumier, C.; Watterson, M. P.; Fleet, G. W. J. Tetrahedron Lett. 2001, 42, 4251. 
106. Torres, E.; Gorrea, E.; Da Silva, P.; Nolis, P.; Branchadell, V.; Ortuno, R. M. Org. Lett. 2009, 11, 2301.

107. Threlfall, R.; Davies, A.; Howarth N. M.; Fisher, J.; Cosstick, R. Chem. Comm. 2008, 585 .

108. Abele, S.; Seiler, P.; Seebach, D. Helv. Chim. Acta 1999, 82, 1559.

119. Seebach, D.; Gademann, K.; Schreiber, J. V.; Matthews, J. L.; Hintermann, T.; Jaun, B. Helv. Chim. Acta 1997, 80, 2033.

110. Seebach, D.; Abele, S.; Gademann, K.; Guichard, G.; Hintermann, T.; Jaun, B.; Matthews, J. L.; Schreiber, J. V. Helv. Chim. Acta 1998, 81, 932.

111. Seebach, D.; Sifferlen, T.; Mathieu, P. A.; Hane, A. M.; Klell, C. M.; Bierbaum, D. J.; Abele, S. Helv. Chim. Acta 2000, 83, 2849.

112. Rueping, M.; Schreiber, J. V.; Lelais, G.; Jaun, B.; Seebach, D. Helv. Chim. Acta 2002, $85,2577$.

113. Martinek, T. A.; Mandity, I. M.; Fulop, L.; Toth, G. K.; Vass, E.; Hollosi, M.; Forro, E.; Fulop, F. J. Am. Chem. Soc. 2006, 128, 13539.

114. Mandity, I. M.; Fulop, L.; Vass, E.; Toth, G. K.; Martinek, T. A.; Fulop, F. Org. Lett. 2010, 12, 5584.

115. Raguse, T. L.; Lai, J. R.; LePlae, P. R.; Gellman, S. H. Org. Lett. 2001, 3, 3963.

116. Daniels, D. S.; Petersson, E. J.; Qiu, J. X.; Schepartz, A. J. Am. Chem. Soc. 2007, 129, 1532.

117. Petersson, E. J.; Craig, C. J.; Daniels, D. S.; Qiu, J. X.; Schepartz, A. J. Am. Chem. Soc. 2007, 129, 5344 .

118. Hetenyi, A.; Mandity, I. M.; Martinek, T. A.; Toth, G. K.; Fulop, F. J. Am. Chem. Soc. 2005, $127,547$.

119. Molski, M. A.; Goodman, J. L.; Craig, C. J.; Meng, H.; Kumar, K.; Schepartz, A. J. Am. Chem. Soc. 2010, 132, 3658.

120. Craig, C. J.; Goodman, J. L.; Schepartz, A. ChemBioChem 2011, 12, 1035.

121. Wang, P. S-P.; Craig, C. J.; Schepartz, A. Tetrahedron 2012, 68, 4342.

122. Molski, M. A.; Goodman, J. L.; Chou, F-C.; Baker, D.; Das, R.; Schepartz, A. Chem. Sci. 2013, 4, 319.

123. Bruckner, A. M.; Chakraborty, P.; Gellman, S. H.; Diederichsen, U. Angew. Chem. Int. Ed. 2003, 42, 4395.

124. Lelais, G.; Seebach, D.; Jaun, B.; Mathad, R. I.; Flögel, O.; Rossi, F.; Campo, M.; Wortmann, A. Helv. Chim. Acta 2006, 89, 361. 
125. Kwon, S.; Jeon, A.; Yoo, S. H.; Chung, I. S.; Lee, H. S. Angew. Chem. Int. Ed. 2010, 49,8232 .

126. Horne, W. S.; Gellman, S. H. Accounts Chem. Res. 2008, 41, 1399.

127. Horne, W. S.; Price, L. P.; Keck, J. L.; Gellman, S. H. J. Am. Chem. Soc. 2007, 129, 4178.

128. Price, J. L.; Horne, W. S.; Gellman, S. H. J. Am. Chem. Soc. 2007, 129, 6376.

129. Martinek, T. A.; Hetenyi, A.; Fulop, L.; Mandity, I. M.; Toth, G. K.; Dekany, I.; Fulop, F. Angew. Chem. Int. Ed. 2006, 45, 2396.

130. Hintermann, T.; Seebach, D. Chimia 1997, 50, 244.

131. Seebach, D.; Abele, S.; Schreiber, J. V.; Martinoni, B.; Nussbaum, A. K.; Schild, H.; Schulz, H.; Hennecke, H.; Woessner, R.; Bitsch, F. Chimia 1998, 52, 734.

132. Shih, C. L.; Gossett, S.; Gruber, J. M.; Grossman, C. S.; Andis, S. L.; Schultz, R. M.; Worzalla, J. F.; Corbett, T. H.; Metz, J. T. Bioorg. Med. Chem. Lett. 1999, 9, 69.

133. Quinn, P. J.; Boldyrev, A. A.; Formazuyk, V. E. Mol. Aspects Med. 1992, 13, 379.

134. Fix, J. A. Pharm. Res. 1996, 13, 1760.

135. Fulop, F. Stud. in Nat. Prod. Chem. 2000, 22, 273.

136. Kuhl, A.; Hahn, M. G.; Dumic, M.; Mittendorf, J. Amino Acids 2005, 29, 89.

137. Steer, D. L.; Lew, R. A.; Perlmutter, P.; Smith, A. I.; Aguilar, M. I. Curr. Med. Chem. 2002, 9, 811 .

138. Riniker, B.; Schwyzer, R. Helv. Chim. Acta 1964, 2357.

139. Rodriguez, M.; Fulcrand, P.; Laur, J.; Aumelas, A.; Bali, J. P.; Martinez, J. J. Med. Chem. 1989, 32, 522.

140. Manning, M.; du Vigneaud V. Biochemistry 1965, 4, 1884.

141. Llinares, M.; Devin, C.; Azay, J.; Berge, G. J.; Fehrentz, A.; Martinez, J. J. Med. Chem. 1989, 32, 522 .

142. Mantey, S. A.; Coy, D. H.; Pradhan, T. K.; Igarashi, H.; Rizo, I. M.; Shen, L.; Hou, W.; Hocart, S. J.; Jensen, R. T. J. Biol. Chem. 2001, 276, 9219.

143. Toth, G.; Keresztes, A.; Tomboly, C.; Peter, A.; Fulop, F.; Tourwe, D.; Navratilova, D.; Varga, E.; Roeske, W. R.; Yamamura, H. J.; Szucs, M.; Borsodi, A. Pure Appl. Chem. 2004, 76, 951 .

144. Nunn, C.; Langenegger, M. R. D.; Schuepbach, E.; Kimmerlin, T.; Micuch, P.; Hurth, K.; Seebach, D.; Hoyer, D. Naunyn-Schmiedeberg's Arch Pharmacol. 2003, 367, 95.

145. Wiegand, H.; Wirz, B.; Schweitzer, A.; Gross, G.; Rodriguez-Perez, M. I.; Andres, H.; Kimmerlin, T.; Rueping, M.; Seebach, D. Chem. Biodiversity 2004, 1, 1812. 
146. Trouche, N.; Wieckowski, S., Sun, W.; Chaloin, O.; Hoebeke, J.; Fournel, S.; Guichard, G. J. Am. Chem. Soc. 2007, 129, 13480.

147. Fournel, S.; Wieckowski, S.; Sun, W.; Trouche, N.; Dumortier, H.; Bianco, A.; Chaloin, O.; Habin, M.; Peter, J.-C.; Schneider, P.; vray, B.; Toes, R. E.; Offringa, R.; Melief, C. J. M.; Hoebeke, J.; Guichard, G. Nat. Chem. Biol. 2005, 1, 377.

148. Oren, Z.; Shai, Y. Biopolymers 1998, 47, 451.

149. Tossi, A.; Sandri, L.; Giangaspero, A. Biopolymers 2000, 55, 4.

150. DeGrado, W. F.; Musso, G. F.; Lieber, M.; Kaiser, E. T.; Kezdy, F. J. Biophys. J. 1982, 37,329 .

151. Hamuro, Y.; Schneider, J. P.; DeGrado, W. F. J. Am. Chem. Soc. 1999, 121, 12200.

152. Liu, D.; DeGrado, W. F. J. Am. Chem. Soc. 2001, 123, 7553.

153. Raguse, T. L.; Porter, E. A.; Weisblum, B.; Gellman, S. H. J. Am. Chem. Soc. 2002, $124,12774$.

154. Epand, R. F.; Raguse, T. L.; Gellman, S. H.; Epand, R. M. Biochemistry 2004, 43, 9527.

155. Porter, E. A.; Wang, X.; Lee, H.-S.; Weisblum, B.; Gellman, S. H. Nature 2000, 404, 545.

156. Porter, E. A.; Weisblum, B.; Gellman, S. H. J. Am. Chem. Soc. 2002, 124, 7324.

157. Porter, E. A.; Weisblum, B.; Gellman, S. H. J. Am. Chem. Soc. 2005, 127, 11516.

158. Maloy, W. L.; Kari, U. P. Biopolymers 1995, 37, 105.

159. Karlsson, A. J.; Pomerantz, W. C.; Weisblum, B.; Gellman, S. H.; Palecek, S. P. J. Am. Chem. Soc. 2006, 128, 12630.

160. Karlsson, A. J.; Pomerantz, W. C.; Neilsen, K. J.; Gellman, S. H.; Palecek, S. P. Acs. Chemical Biology 2009, 4, 567.

161. Akkarawongsa, R.; Potocky, T. B.; English, E. P.; Gellman, S. H.; Brandt, C. R. Antimicrobal Agents and Chemotherapy 2008, 52, 2120.

162. Werder, M.; Hauser, H.; Abele, S.; Seebach, D. Helv. Chim. Acta 1999, 82, 1774.

163. Gelman, M. A.; Richter, S.; Cao, H.; Umezawa, N.; Gellman, S. H.; Rana, T. M. Org. Lett. 2003, 5, 3563.

164. Eldred, S. E.; Pancost, M. R.; Otte, K. M.; Rozema, D.; Stahl, S. S.; Gellman, S. H. Bioconj. Chem. 2005, 16, 694.

165. Kritzer, J. A; Lear, J. D.; Hodsdon, M. E.; Schepartz, A. J. Am. Chem. Soc. 2004, 126, 9468 .

166. Kritzer, J. A.; Hodsdon, M. E.; Schepartz, A. J. Am. Chem. Soc. 2005, 127, 4118. 
167. Michel, J.; Harker, E. A.; Tirado-Rives, J.; Jorgensen, W. L.; Schepartz, A. J. Am. Chem. Soc. 2009, 131, 6356.

168. Bautista, A. D.; Appelbaum, J. S.; Craig, C. J.; Michel, J.; Schepartz, A. J. Am. Chem. Soc. 2010, 132, 2904.

169. Chene, P. Nat. Rev. Cancer 2003, 3, 102.

170. Stephens, O. M.; Kim, S.; Welch, B. D.; Hodsdon, M. E.; Kay, M. S.; Schepartz, A. J. Am. Chem. Soc. 2005, 127, 13126.

171. Kritzer, J. S.; Stephens, O. M.; Guarracino, D. A.; Reznik, S. K.; Schepartz, A. Bioorg. Med. Chem. 2005, 13, 11.

172. Horne, W. S.; Johnson, L. M.; Ketas, T. J.; Klasse, P. J.; Lu, M.; Moore, J. P.; Gellman, S. H. Proc. Natl. Acad. Sci. USA 2009, 106, 14751.

173. Horne, S. W.; Boersma, M. D.; Windsor, M. A.; Gellman, S. H. Angew. Chem. Int. Ed. 2008, 47, 2853.

174. Lee, E. F.; Sadowsky, J. D.; Smith, B. J.; Czabotar, P. E.; Peterson-Kaufman, K. J.; Colman, P. M.; Gellman, S. H.; Fairlie, W. D. Angew. Chem. Int. Ed. 2009, 48, 4318.

175. Imamuran, Y.; Watanabe, N.; Umezawa, N.; Iwatsubo, T.; Kato, N.; Tomita, T.; Higuchi, T. J. Am. Chem. Soc. 2009, 131, 7353.

176. Merrifield, R. B. J. Am. Chem. Soc. 1963, 85, 2149.

177. Carpino, L. A.; Acc. Chem. Res. 1987, 20, 401.

178. Murray, J. K.; Gellman, S. H. Org. Lett. 2005, 7, 1517.

179. Murray, J. K.; Gellman, S. H. J. Comb. Chem. 2006, 8, 58.

180. Bayer, E. Angew. Chem. Int. Ed. 1991, 30, 113.

181. Carpino, L. A. J. Am. Chem. Soc. 1993, 115, 4379.

182. Kaiser, E.; Colescott, R. L.; Bossinger, C. D.; Cook, P. J. Anal. Biochem. 1970, 34, 595.

183. http://www.phenomenex.com

184. http://www.jascoinc.com/Home.aspx

185. http://www.thermoscientific.com

186. http://www.home.agilent.com

187. http://www.bruker-biospin.com/nmr.html

188. Bax, A.; Davis, D. G. J. Magn. Reson. 1985, 63, 207.

189. Braunschweiler, L.; Ernst, R. R. J. Magn. Reson. 1983, 53, 521.

190. Bax, A.; Davis, D. G. J. Magn. Reson. 1985, 65, 355.

191. http://www.jascoinc.com/Products/Spectroscopy 
192. http://www.jascoinc.com/Spectra_Manager_II.asp

193. http://www.perkinelmer.com/catalog/family/id/spectrum\%20two

194. http://www.chemcomp.com

195. Halgren, T. A. J. Comput. Chem. 1996, 17, 490.

196. Halgren, T. A. J. Comput. Chem. 1999, 20, 720.

197. Frisch M. J. et al., GAUSSIAN 03 (Revision C.02), Gaussian, Inc., Pittsburgh, PA, 2004. http://www.gaussian.com

198. Huo, R.; Wehrens, R.; van Duynhoven, J.; Buydens, L. M. C. Anal. Chim. Acta 2003, $490,231$.

199. Szakonyi, Z.; Martinek, T. A.; Sillanpaa, R.; Fulop, F. Tetrahedron: Asymmetry 2008, $19,2296$.

200. Beke, T.; Csizmadia, I. G.; Perczel, A. J. Comput. Chem. 2004, 25, 285.

201. Mohle, K.; Gunther, R.; Thormann, M.; Sewald, N.; Hofmann, H. J. Biopolymers 1999, 50, 167.

202. Daura, X.; Bakowies, D.; Seebach, D.; Fleischhauer, J.; van Gunsteren, W. F.; Kruger, P. Eur. Biophys. J. 2003, 32, 661.

203. Kim, H. T.; Park, J. K. Polym. Bull. 1998, 41, 325.

204. Skalski, B.; Rapp, M.; Suchowiak, M.; Golankiewicz, K. Tetrahedron Lett. 2002, 43, 5127.

205. Winkler, J. D.; Piatnitski, E. L.; Mehlmann, J.; Kasparec, J.; Axelsen, P. H. Angew. Chem. Int. Ed. 2001, 40, 743.

206. Pomerantz, W. C.; Yuwono, V. M.; Pizzey, C. L.; Hartgerink, J. D.; Abbott, N. L.; Gellman, S. H. Angew. Chem. Int. Ed. 2008, 47, 1.

207. Petersson, E. J.; Schepartz, A. J. Am. Chem. Soc. 2008, 130, 821.

208. Yang, Z.; Liang, G.; Ma, M.; Gao, Y.; Xu, B. Small 2007, 3, 558.

209. Jagannadh, B.; Reddy, M. S.; Rao, C. L.; Prabhakar, A.; Jagadeesh, B.; Chandrasekhar, S. Chem. Comm. 2006, 4847.

210. Rua, F.; Boussert, S.; Parella, T.; Diez-Perez, I.; Branchadell, V.; Giralt, E.; Ortuno, R. M Org. Lett. 2007, 9, 3643.

211. Beke, T.; Csizmadia, I. G.; Perczel, A. J. Am. Chem. Soc. 2006, 128, 5158.

212. LePlae, P. R.; Fisk, J. D.; Porter, E. A.; Weisblum, B.; Gellman, S. H. J. Am. Chem. Soc. 2002, 124, 6820 . 
213. Torres, E.; Gorrea, E.; Burusco, K. K.; Da Silva, E.; Nolis, P.; Rua, F.; Boussert, S.; Diez-Perez, I.; Dannenberg, S.; Izquierdo, S.; Giralt, E.; Jaime, C.; Branchadell, V.; Ortuno, R. M. Org. Biomol. Chem. 2010, 8, 564.

214. Angelici, G.; Falini, G.; Hofmann, H. J.; Huster, D.; Monari, M.; Tomasini, C. Chem. Eur. J. 2009, 15, 8037.

215. Berlicki, L.; Pilsl, L.; Weber, E.; Mandity, I. M.; Cabrele, C.; Martinek, T. A.; Fulop, F.; Reiser, O. Angew. Chem. Int. Ed. 2012, 51, 2208.

216. Townsley, L. E.; Tucker, W. A.; Sham, S.; Hinton, J. F. Biochemistry 2001, 40, 11676.

217. Arvidsson, P. I.; Ryder, N. S.; Weiss, H. M.; Gross, G.; Kretz, O.; Woessner, R.; Seebach, D. ChemBioChem 2003, 4, 1345.

218. Chakrabarartty, A.; Doig, A, J.; Baldwin, R. L. Proc. Natl. Acad. Sci. USA 1993, 90, 11332.

219. Hart, S. A.; Bahadoor, A. B. F.; Matthews, E. E.; Qiu, X. Y. J.; Schepartz, A. J. Am. Chem. Soc. 2003, 125, 4022.

220. Brown, R. A.; Marcelli, T.; De Poli, M.; Sola, J.; Clayden, J. Angew. Chem. Int. Ed. 2012, 51, 1395.

221. Demizu, Y.; Doi, M.; Sato, Y.; Tanaka, M.; Okuda, H.; Kurihara, M. Chem. Eur. J. 2011, 17, 11107.

222. Frisch M. J. et al., GAUSSIAN 09 (Revision A.01), Gaussian, Inc., Wallingford, CT, 2009. http://www.gaussian.com 
Annex 